\title{
Nitric Oxide Participates in the Complex Interplay of Defense-Related Signaling Pathways Controlling Disease Resistance to Sclerotinia sclerotiorum in Arabidopsis thaliana
}

\author{
Laure Perchepied, ${ }^{1}$ Claudine Balagué, ${ }^{1}$ Catherine Riou, ${ }^{1}$ Clotilde Claudel-Renard, ${ }^{2}$ Nathalie Rivière, ${ }^{3}$ \\ Bruno Grezes-Besset, ${ }^{2}$ and Dominique Roby ${ }^{1}$ \\ ${ }^{1}$ Laboratoire des Interactions Plantes-Microorganismes (LIPM), UMR CNRS-INRA 2594/441, BP 52627, 31320 Castanet- \\ Tolosan cedex, France; ' 2 Laboratoire de Biologie Cellulaire et Moléculaire, BIOGEMMA, Domaine de Sandreau, Mondonville, \\ France; ${ }^{3}$ Upstream Genomics Research Group, Transcriptomics Team, BIOGEMMA, Z.I. du Brezet, 8, Rue des Frères Lumière, \\ 63028 Clermont-Ferrand Cedex 2, France
}

Submitted 18 January 2010. Accepted 10 March 2010.

\begin{abstract}
Studies of the interaction between Arabidopsis thaliana and the necrotrophic fungal pathogen Sclerotinia sclerotiorum have been hampered by the extreme susceptibility of this model plant to the fungus. In addition, analyses of the plant defense response suggested the implication of a complex interplay of hormonal and signaling pathways. To get a deeper insight into this host-pathogen interaction, we first analyzed the natural variation in Arabidopsis for resistance to $S$. sclerotiorum. The results revealed a large variation of resistance and susceptibility in Arabidopsis, with some ecotypes, such as Ws-4, Col-0, and Rbz-1, being strongly resistant, and others, such as Shahdara, Ita-0, and Cvi-0, exhibiting an extreme susceptibility. The role of different signaling pathways in resistance was then determined by assessing the symptoms of mutants affected in the perception, production, or transduction of hormonal signals after inoculation with $S$. sclerotiorum. This analysis led to the conclusions that $i)$ signaling of inducible defenses is predominantly mediated by jasmonic acid and abscisic acid, influenced by ethylene, and independent of salicylic acid; and ii) nitric oxide (NO) and reactive oxygen species are important signals required for plant resistance to $S$. sclerotiorum. Defense gene expression analysis supported the specific role of NO in defense activation.
\end{abstract}

In response to pathogen attack, plants have developed complex signaling and defense mechanisms in order to protect themselves. Plant defenses are regulated through a complex network of transduction pathways involving a number of signaling molecules, including reactive oxygen species (ROS), nitric oxide (NO), salicylic acid (SA), jasmonic acid (JA), and ethylene (ET) (Kunkel and Brooks 2002). A number of mutants affecting the biosynthesis or transduction of these signals are available (Kunkel and Brooks 2002). In addition to these,

L. Perchepied and C. Balaqué made equal contributions to this work.

Corresponding author: Dominique Roby; Telephone: +1 3305612853 26; Fax: +1 3305612850 61; E-mail: dominique.roby@ toulouse.inra.fr

* The $\boldsymbol{e}$-Xtra logo stands for "electronic extra" and indicates that two supplementary tables and one supplementary figure are published online. mutational analyses in Arabidopsis have uncovered genes acting as positive regulators that are required for resistance conferred by several resistance $(R)$ genes. EDS1 and NDR1 are such regulators and are hypothesized to belong to two downstream pathways triggered by $R$ genes, encoding two kinds of protein structures (toll interleukin 1 receptor-nucleotide binding site-leucine-rich repeat [TIR-NB-LRR] or coiled-coil NBLRR, respectively), determining which downstream factors are required (Aarts et al. 1998; Century et al. 1995; Parker et al. 1996). Additional, independent pathways have also been found (Bittner-Eddy and Beynon 2001; McDowell and Dangl 2000). Subsequently, downstream resistance components, such as RAR1 and SGT1, have been discovered, which are required for signaling by specific sets of resistance genes (Austin et al. 2002; Azevedo et al. 2002; Muskett et al. 2002; Tör et al. 2002; Tornero et al. 2002). Plant mitogen-activated protein kinases (MPK) such as MPK4 have also been implicated as components of defense signaling pathways (Brodersen et al. 2006; Petersen et al. 2000).

Thus, a number of signaling components have been identified which reveal that resistance to different pathogen types is achieved through activation of specific signaling pathways, depending on the $\mathrm{R}$ protein structures, the invasion mode of the pathogen, and, certainly, on some other, still unknown parameters. For instance, JA/ET pathways seem to be more related to necrotrophic pathogens, whereas the SA pathway is more often used by biotrophic pathogens. Abscisic acid (ABA) has recently been shown to act as an essential signal for different pathogens and, more specifically, pathogens affecting JA biosynthesis (Adie et al. 2007; Kaliff et al. 2007; Mauch-Mani and Mauch 2005; Ton and Mauch-Mani 2004). In addition, these pathways do not function independently but interconnect cooperatively and antagonistically through a complex regulatory network (Glazebrook 2005; Thomma et al. 2001). The dynamics of these interactions are not clearly understood but they are crucial to fine-tuning induction of defenses in response to different pathogens. A limited number of models is currently studied; therefore, the characterization of novel plant-pathogen interactions should enable a better understanding of these regulatory networks and the discovery of new plant defense mechanisms. In this context, we have studied the interaction between Sclerotinia sclerotiorum (S. sclerotiorum) and Arabidopsis thaliana. 
S. sclerotiorum is a necrotrophic fungal pathogen that causes a major disease in many crop species worldwide. Over 400 plant species have been reported to be susceptible to this pathogen, including important crops such as oilseed rape and sunflower (Purdy 1979). Genetic resistance to $S$. sclerotiorum exists in sunflower and oilseed rape (Bert et al. 2002; Liu et al. 2005; J. Zhao et al. 2006a). However, the nature of this resistance, polygenic and partial, and the large effect of environmental conditions on disease development make it difficult to improve resistance using classical breeding methods.

The molecular bases of plant-S. sclerotiorum interactions remain poorly understood. However, Sclerotinia spp. have been shown to produce a number of pathogenicity factors, including cell-wall-degrading enzymes (Riou et al. 1991) and oxalic acid, known to play a key role in the interaction (Godoy et al. 1990; Guimaraes and Stotz 2004; Kim et al. 2008). Recently, generation of transgenic plants degrading oxalic acid have been shown to be more resistant to Sclerotinia spp. (Donaldson et al. 2001; Livingston et al. 2005). Oxalate-degrading bacteria can also protect $A$. thaliana and crop plants against necrotrophic fungi (Schoonbeek et al. 2007). Interestingly, the model plant $A$. thaliana has been shown to be naturally infected by $S$. sclerotiorum (Wang et al. 2008), opening the way to basic studies. However, previous reports indicated that the extreme susceptibility of Arabidopsis to this pathogen would prevent the characterization of genetic and molecular determinants of resistance or susceptibility (Dai et al. 2006). For this reason, subsequent studies have been conducted using an oxalate-deficient S. sclerotiorum strain with reduced aggressiveness (Godoy et al. 1990). At this point, it should be noted that oxalate is not only an essential pathogenicity factor of S. sclerotiorum but also a key actor of the interactions of the fungus with its hosts (Cessna et al. 2000; Guimaraes and Stotz 2004). In addition, some components of the ABA, JA, SA, and ET signaling have been shown to be implicated in defense to $S$. sclerotiorum (Guo and Stotz 2007). These studies led to inter- esting but fragmentary data, because a limited number of mutants were analyzed for each pathway and some pathways were not studied, such as those involving early components of the resistance pathways, including EDS1, NDR1, PAD4, and signaling molecules such as NO and ROS.

To get a deeper insight into the Arabidopsis-S. sclerotiorum host-pathogen interaction, we have analyzed the natural variation in Arabidopsis for resistance to $S$. sclerotiorum and studied the plant molecular defense pathways involved in resistance through genetic and genomic analysis. This combined analysis allowed us to i) reveal an unexpectedly large variation of resistance and susceptibility in Arabidopsis, ii) clarify the role of each signaling pathway using several components of each pathway and a natural $S$. sclerotiorum strain, and iii) identify $\mathrm{NO}$ and ROS as important signals required for plant resistance to $S$. sclerotiorum. Finally, the analysis in oilseed rape of different defense marker genes (previously analyzed in Arabidopsis) indicates that their regulation is largely conserved in response to $S$. sclerotiorum infection in this crop.

\section{RESULTS}

\section{Natural variation for $S$. sclerotiorum resistance} in A. thaliana.

In order to investigate the genetic and molecular determinants of resistance or susceptibility to S. sclerotiorum in Arabidopsis, we first analyzed natural variation of this trait. Our aim was to determine whether the extreme susceptibility previously reported in Arabidopsis (Dai et al. 2006) is a general feature of this model species or is restricted to only some ecotypes. We also wanted to identify susceptible and resistant ecotypes to be able to evaluate the susceptibility or resistance of defense signaling mutants.

For this purpose, more than 50 ecotypes of $A$. thaliana were tested for their response to the fungal pathogen (Fig. 1). In all, 45 of these accessions are part of a core collection of 48 eco-

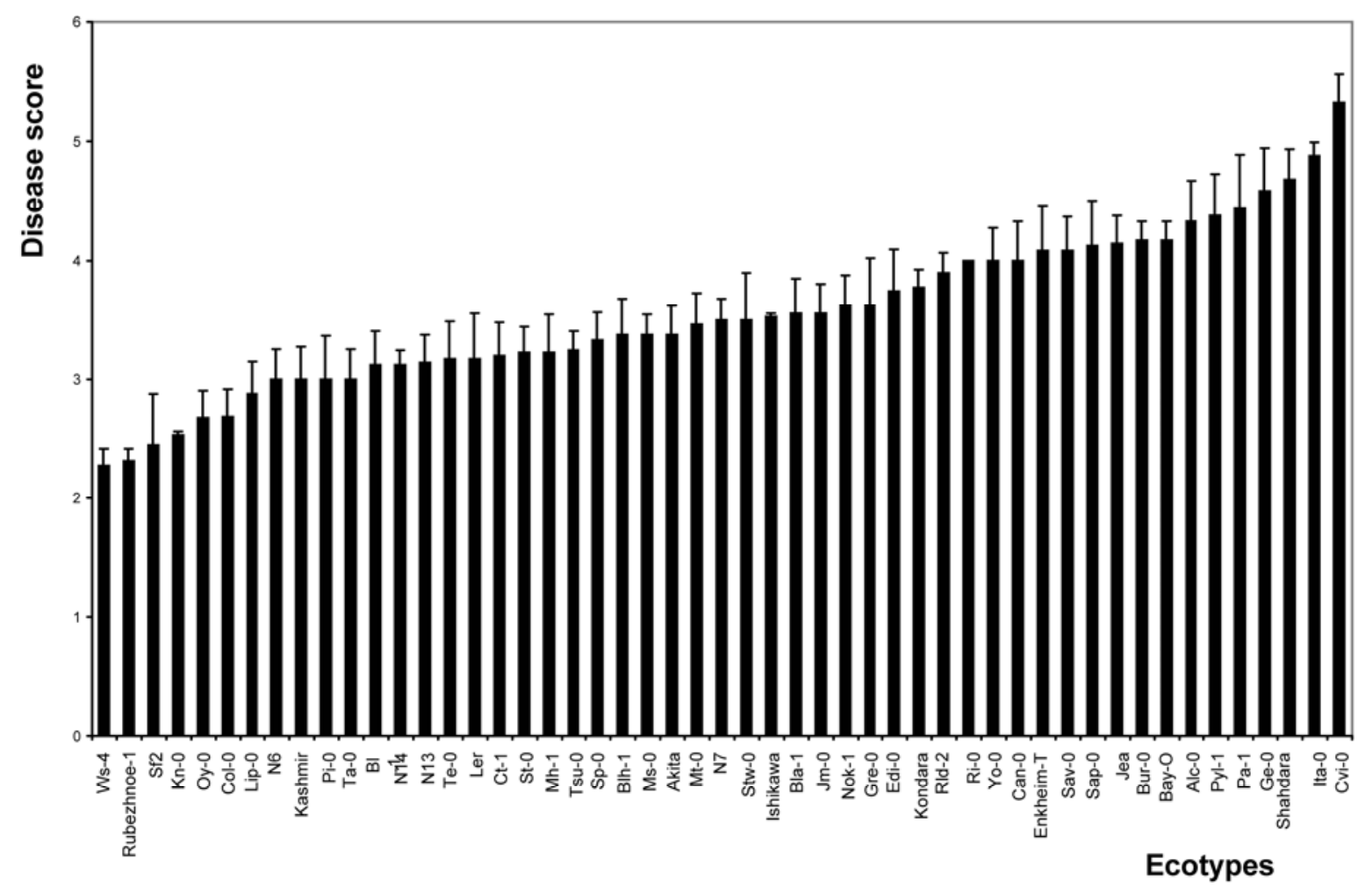

Fig. 1. Natural variation of resistance to Sclerotinia sclerotiorum among Arabidopsis accessions. Leaves of 4-week-old plants were inoculated with S. sclerotiorum (strain S55). Each inoculated plant was scored 7 days after inoculation. Means and standard errors were calculated from scoring at least six plants. 
types, estimated to correspond to $100 \%$ of the variation present in Arabidopsis (McKhann et al. 2004). The other accessions (six ecotypes) are currently used in the laboratory or correspond to parental accessions of recombinant inbred line populations. Plant resistance to $S$. sclerotiorum was evaluated using a semiquantitative test with a scoring scale of 0 to 6 , based on measurement every 2 days, of the fungal colonization of the whole plant after inoculation of one leaf, until 14 days postinoculation (dpi). Fungal colonization varied continuously in the different accessions (Fig. 1). This result indicates that some ecotypes exhibit extremely contrasting phenotypes, such as Ws-4 and Rubezhnoe-1 (Rbz-1), which are highly resistant to S. sclerotiorum, and Shahdara (Sha), Ita-0, and Cvi-0, which are highly susceptible (Fig. 1). Additionally, many ecotypes show an intermediate phenotype (Fig. 1). Thus, resistance to $S$. sclerotiorum exists and is a quantitative trait in Arabidopsis, as previously reported in crops (Bert et al. 2002; Zhao et al. 2006a). Based on these results, the ecotypes Rbz-1 and Sha were used as the resistant and susceptible controls, respectively, for further experiments.

\section{Contribution of the JA, ET, SA, and ABA pathways.}

To determine the role of SA, JA, ET, and ABA in resistance to $S$. sclerotiorum, mutants affected in the perception, production, or transduction of these hormonal signals were inoculated and the symptoms were assessed as previously described. Most of these mutants are available in the Col- 0 genetic background, evaluated as strongly resistant (Fig. 1). Mutants affected in the early steps of signaling pathways leading to resistance to biotrophs were also analyzed ( $e d s 1, p a d 4$, and $n d r 1-1$ ) (Century et al. 1995; Falk et al. 1999; Jirage et al. 1999). These mutants were not affected in their response to S. sclerotiorum (Supplementary Fig. 1A and B).

Consistent with previous analyses of JA-deficient mutants (Guo and Stotz 2007), and the described role of JA in the resistance to necrotrophic fungi (Lorenzo and Solano 2005), the JA-insensitive coil-1 mutant was highly susceptible to $S$. sclerotiorum (Fig. 2A and B), indicating that JA is a major signal for activation of defenses against this fungus. However, jar1-1, a jasmonate-resistant mutant shown to exhibit enhanced sensitivity to the fungal necrotroph Pythium irregulare, was not affected for responsiveness to S. sclerotiorum. $J A R 1$ encodes an enzyme that generates the jasmonyl-isoleucine (JA-Ile) conjugate (Staswick and Tiryaki 2004) that engages the COI1 pathway (Thines et al. 2007). Our results indicate that some (but not all) components of the jasmonatesignaling cascade, such as COI1, are essential for resistance to $S$. sclerotiorum.

Consistent with results of Guo and Stotz (2007), the ETinsensitive ein2-1 mutant showed a significantly increased susceptibility to the fungus (although clearly lower than coil-1), indicating that ET is required for defense (Fig. 2A and B). However, EIN4, EIN3, ERF1, and EIN7, which are positive regulators of the ET signaling pathway (ET receptor EIN4, transcriptional factors EIN3 and ERF1, and exoribonuclease regulator EIN7) (Guzman and Ecker 1990; Roman et al. 1995), did not appear to play a role in resistance to the fungus. Similar results were found for the dominant eto2-1 mutation, which affects the C-terminal domain of the ACC synthase 5 (ACS5) and which, as a result, increases the production of ET (Chae et al. 2003). In contrast, eto3, which also affects an ACC synthase (ACS9) (Chae et al. 2003), is significantly affected in resistance to $S$. sclerotiorum, although to a lesser extent compared with ein2-1. These results indicate that ET is important for fully active plant defenses. However, the fact that only two mutations (eto3 and ein2-1) exerting different effects on the ET pathway (overproduction and insensitivity) affect the plant response suggests that ET might exert an indirect effect on resistance to $S$. sclerotiorum, through cooperative or antagonistic crosstalk with other regulatory pathways.

Interestingly, SA mutants affected in SA accumulation (sidl/ eds5 and sid2/eds16) or signaling (npr1-1) and nahG transgenic plants impaired in SA accumulation (Cao et al. 1994; Friedrich et al. 1995; Rogers and Ausubel 1997; Wildermuth et al. 2001) did not show any significant difference in resistance to $S$. sclerotiorum compared with the wild type (Fig. 2A and C). The hypersusceptibility previously described for the nprl-1 mutant was not reproduced in our experiments (Guo and Stotz 2007). These results clearly establish that SA does not contribute to resistance to $S$. sclerotiorum.

Finally, in agreement with previous reports concerning the essential role of ABA for plant resistance to different pathogens (Adie et al. 2007; Guimaraes and Stotz 2004; HernandezBlanco et al. 2007), all ABA-deficient or -insensitive ( $a b a$ or $a b i$, respectively) mutants tested showed increased susceptibility to $S$. sclerotiorum in the background Ler (ecotype intermediate-resistant to $S$. sclerotiorum) (Fig. 2A and D). However, in the Col-0 background, only aba2-3, a mutant impaired in ABA biosynthesis, was significantly altered in response to the fungus, suggesting the implication of other regulators in combination with $\mathrm{ABA}$.

The contribution of JA, SA, ET, and ABA pathways was further evaluated at the molecular level by expression analysis of JA-, SA-, ET-, and ABA-dependent genes (Fig. 3A). In good agreement with the extreme susceptibility of coil-1, expression of VSPl, a gene associated with the JA pathway, was induced early in response to inoculation in the resistant ecotype, whereas this marker was downregulated in the susceptible ecotype. This was the only defense gene positively regulated in the very early stages of the infection $(6 \mathrm{~h}$ postinoculation [hpi]), and this induction was transient, low transcript levels being detected in the later stages of infection. At 24 or $48 \mathrm{hpi}$, all the other defense markers tested $(P R-1$, $P D F 1-2$, and $R D 20$, genes associated with SA, ET, and ABA pathways, respectively) were highly expressed in the resistant ecotype and expressed at lower levels in the susceptible ecotype. This was also observed at $72 \mathrm{hpi}$, except for VSP1 and $P R 1$, which were highly expressed in the susceptible ecotype, probably as a result of massive colonization of the plant by the fungal pathogen.

Many members of the WRKY transcription factors are involved in the regulation of transcriptional reprogramming of the immune response; therefore, some well-known members were tested in the context of this interaction (Fig. 3B). WRKY33 and 40, known as positive and negative regulators of defense, respectively (Eulgem and Somssich 2007), were found to be highly expressed as soon as 24 hpi in the resistant ecotype, whereas they were expressed at lower levels in the susceptible ecotype. However, at $2 \mathrm{dpi}$, similar levels of expression were observed in both ecotypes. WRKY70 and MYC2 have been shown to regulate the selection of signaling pathways in plant defense, especially for JA-, SA-, and ET-mediated pathways (Li et al. 2004, 2006; Lorenzo et al. 2004). Interestingly, WRKY70, which acts as a negative regulator of the JA pathway, was downregulated in the two ecotypes in the very early stages of the interaction, then induced 1 or 2 dpi in the resistant ecotype. AtMYC2, which negatively regulates JAregulated genes involved in defense responses against pathogens, showed a similar expression profile. These results suggest a negative role for WRKY70 and MYC2 in resistance to $S$. sclerotiorum, in good agreement with our data showing a major role for JA in this interaction. All together, these data show a general defense reprogramming during the interaction, with an emphasis on the JA pathway. 
ROS and NO are required for defense to $S$. sclerotiorum.

NO in synergy with ROS has been shown to be rapidly generated during many plant-pathogen interactions (Besson-Bard et al. 2008; Delledone 2005; Wendehenne et al. 2004). In the case of the Arabidopsis-S. sclerotiorum interaction, oxalic acid, a major pathogenicity factor of the fungus, has been reported to modulate ROS production (Cessna et al. 2000; Guo and Stotz 2007). However, the exact role of these signaling molecules in resistance or susceptibility has not been addressed.

In agreement with previous reports, staining with 3,3'-diaminobenzidine (DAB) indicated $\mathrm{H}_{2} \mathrm{O}_{2}$ accumulation during the interaction (Fig. 4A). This production is observed earlier (20 hpi) in the resistant ecotype (Rbz-1) compared with the susceptible one (Sha), where $\mathrm{H}_{2} \mathrm{O}_{2}$ accumulates at high levels 48 hpi. These results were confirmed by using the $\mathrm{H}_{2} \mathrm{O}_{2}$-sensitive fluorescent dye 2',7'-dichlorofluorescein diacetate $\left(\mathrm{H}_{2} \mathrm{DCF}\right.$ DA) for detection by microscopy and for fluorescence intensity measurement (Fig. 4A and B). The resistant ecotypes Col0 and Rbz-1 show a higher production of $\mathrm{H}_{2} \mathrm{O}_{2} 20$ hpi compared with the susceptible ecotype Sha whereas, at $30 \mathrm{hpi}$, no significant difference could be observed between the different ecotypes. Noninoculated controls produced a similar amount of $\mathrm{H}_{2} \mathrm{O}_{2}$ during the time course of the experiment and in the different genetic backgrounds (data not shown).
A

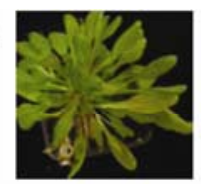

Col-0

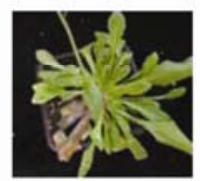

npr1-1

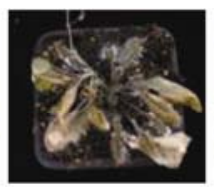

coi1-1

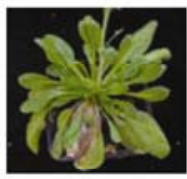

sid1/eds5

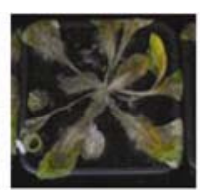

ein2-1

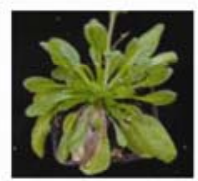

sid2/eds16

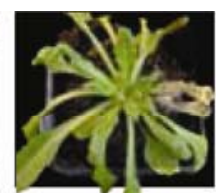

oxerf1

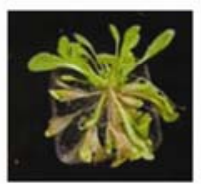

nahG

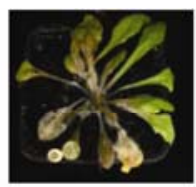

eto3

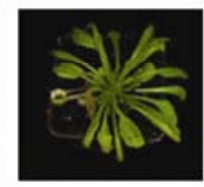

aba2-3

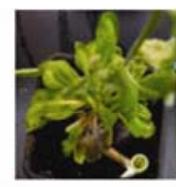

Ler

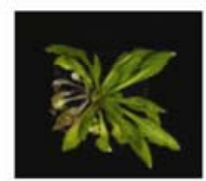

abi5

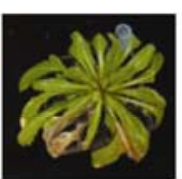

Rbz-1

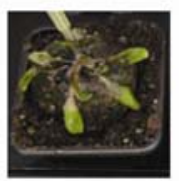

aba3-2

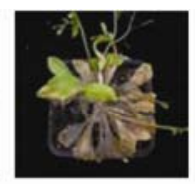

Sha

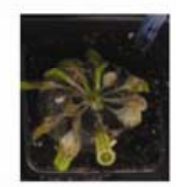

abi1-1

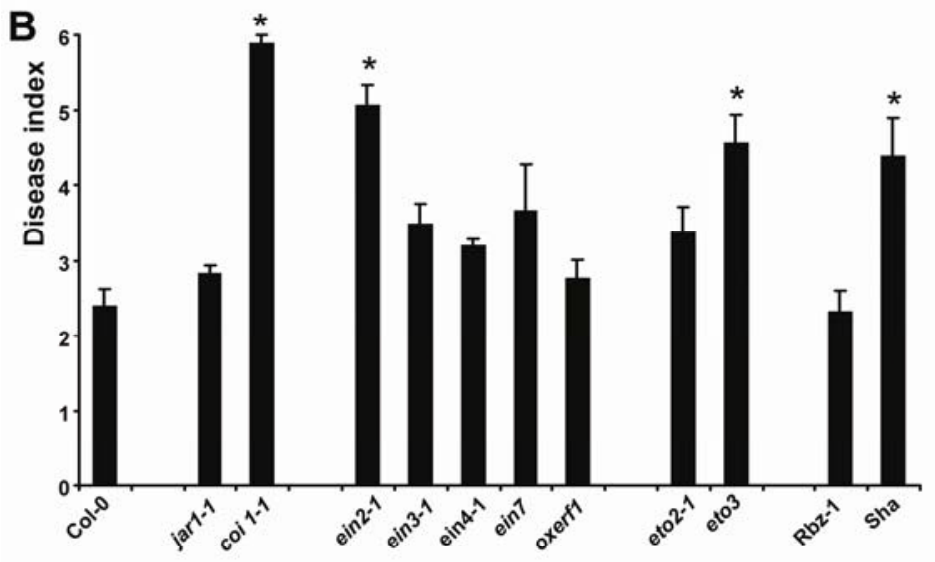

C
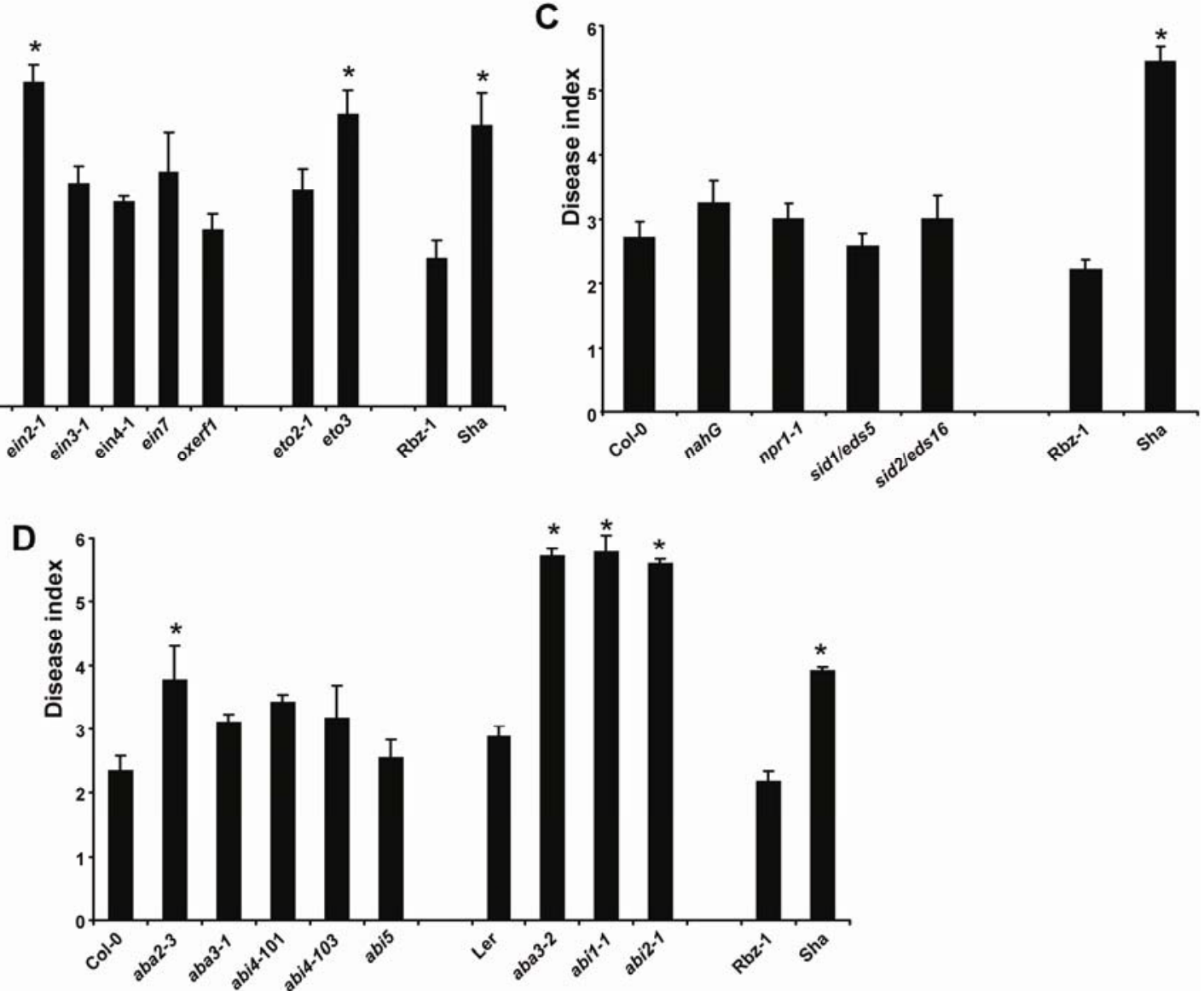

Fig. 2. Effect of mutations affecting jasmonic acid (JA), ethylene (ET), salicylic acid (SA), and abcisic acid (ABA) production and signaling pathways on resistance to Sclerotinia sclerotiorum. Leaves of 4-week-old plants were inoculated with S. sclerotiorum (strain S55) and the disease score was evaluated 7 days postinoculation. A, Four week-old plants inoculated with S. sclerotiorum. B, Disease score of each mutant of the JA and the ET pathways was evaluated 7 days after inoculation compared with the wild-type ecotypes Col-0 (genetic background of the mutants), Rbz- 1 (resistant ecotype), and Sha (susceptible ecotype). C, Disease score of each mutant of the SA pathway was evaluated 7 days after inoculation compared with the wild-type ecotypes. D, Disease score of each mutant of the ABA pathways was evaluated 7 days after inoculation compared with the wild-type ecotypes Col-0 and Ler (genetic backgrounds of the different mutants). Means and standard deviation were calculated from scoring at least 6 plants. A significant difference in susceptibility for a mutant or accession compared with the wild-type Col-0 is indicated with an asterisk (B and D, $P<0.01 ; \mathrm{C}, P<0.05$ ). 
NO was detected by 4,5-diaminofluorescein diacetate (DAF2DA)-mediated fluorescence. By microscopic observation of infected areas, we clearly observed that more cells showed accumulation of NO in the zone adjacent to the infection area at early time points (16 hpi) in the resistant ecotype compared with the susceptible ecotype (Fig. 5A). These results were confirmed by fluorescence measurement (Fig. 5B). However, at later time points (20 hpi), NO levels detected in the susceptible and resistant ecotypes were not significantly different. NO production also occurred in noninoculated leaf samples, probably as a result of constitutive NO production or the stress due to the inoculation procedure. Leaf NO production was significantly reduced by the mammalian NO synthase (NOS) inhibitor L-NAME (37\% inhibition) (data not shown).

To further characterize the plant molecular response for ROS and $\mathrm{NO}$ generation, analysis of the expression of $R B O H-D$ and
$R B O H-F$, known to be involved in ROS production (Mittler et al. 2004; Torres et al. 2002), and of NIA1 and NIA2, which participate in NO generation during signaling processes (BessonBard et al. 2008; Bright et al. 2006; Garcia-Matta and Lamattina 2003; Wilkinson and Crawford 1993), was performed in susceptible (Sha) and resistant (Rbz-1) plants (Figs. 4C and 5C). During the course of the interaction with $S$. sclerotiorum, all these genes were induced as soon as $24 \mathrm{hpi}$, and their expression level was generally higher in the resistant ecotype compared with the susceptible one. Only NIAl expression exhibited a different profile and was reduced during the early stages of the interaction.

Taken together, these results indicate that ROS and NO are early-induced signals during the interaction between Arabidopsis and S. sclerotiorum. Additionally, generation of these signals and expression of related genes appear to be correlated with resistance, at least at the early stages of the interaction.

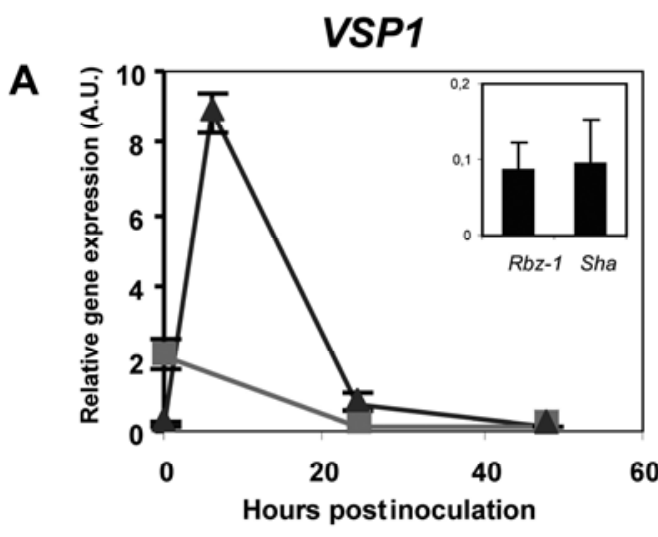

PR1

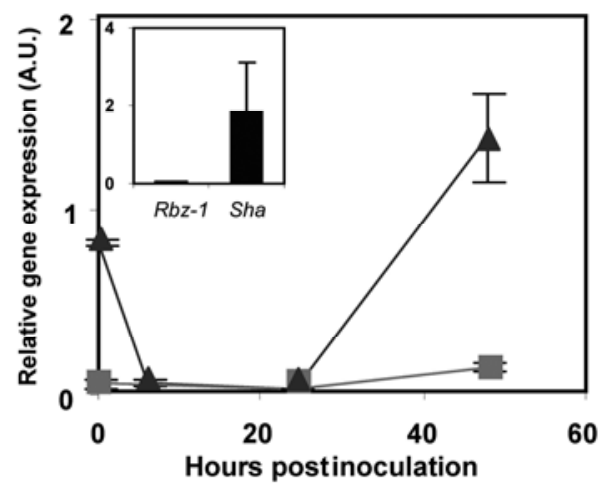

B WRKY-33

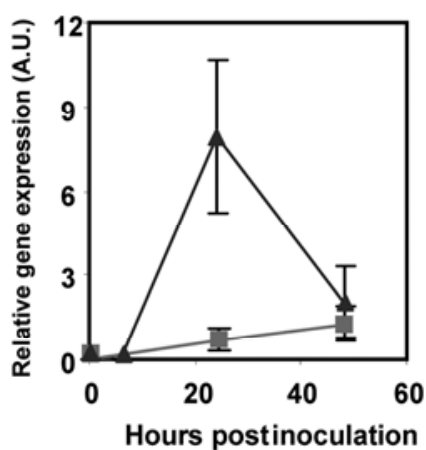

WRKY-40

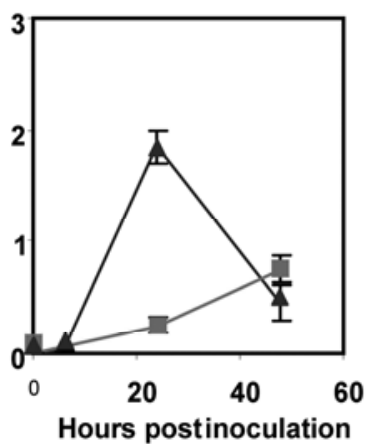

PDF1-2
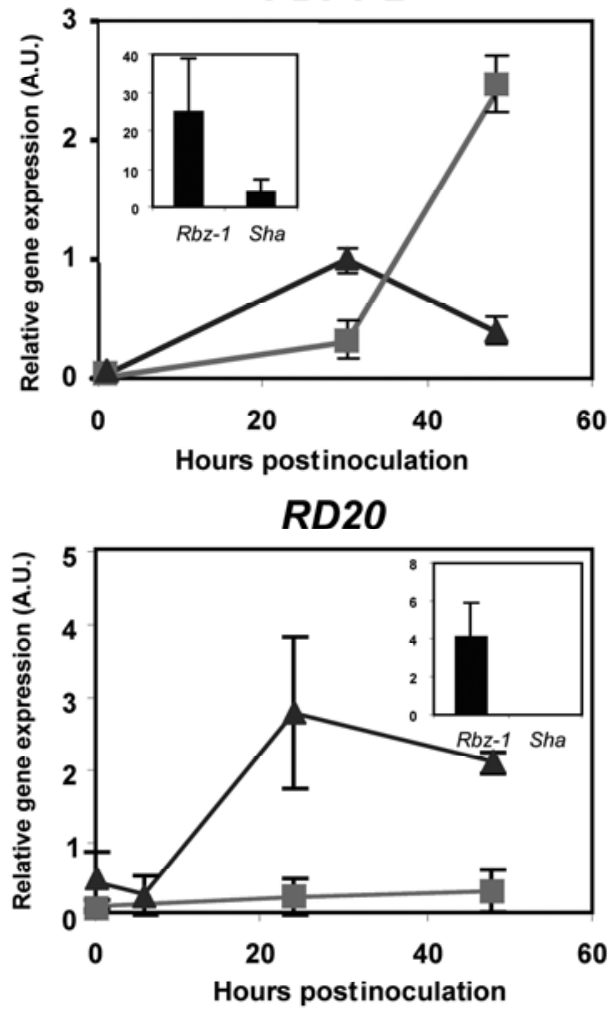

WRKY-70

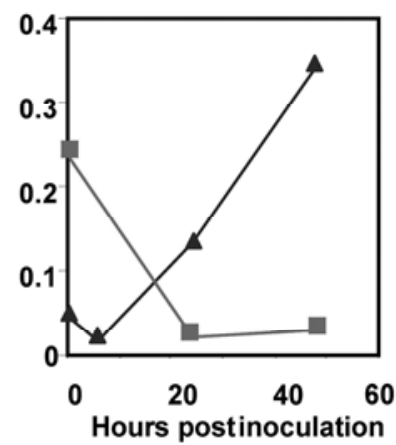

MYC-2

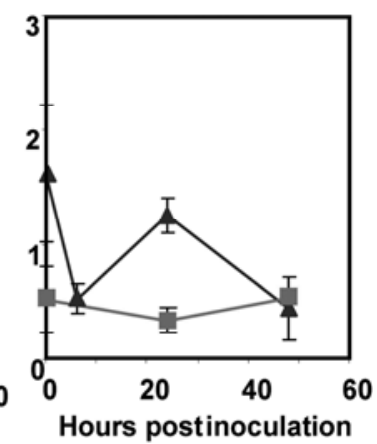

Fig. 3. Defense gene expression in susceptible and resistant ecotypes of Arabidopsis thaliana after inoculation with Sclerotinia sclerotiorum. Transcript levels of $\mathbf{A}$, defense genes or $\mathbf{B}$, transcriptional regulators were evaluated by quantitative reverse-transcription polymerase chain reaction. Leaves of 4-week-old plants of Rbz-1 (resistant, triangles) and Sha (susceptible, squares) were inoculated with S. sclerotiorum (strain S55) and harvested at different times after inoculation (box: $72 \mathrm{~h}$ postinoculation). Each measurement is an average of two replicates and experiments were repeated two times with similar results. The expression values of each gene were normalized using the expression level of $\beta$-tubulin 4 as an internal standard. Mean values and standard errors were calculated from two independent experiments. A.U., arbitrary units. 
In order to genetically determine the role of these signaling molecules during the interaction, mutants altered in their production were tested for their response to S. sclerotiorum: the NO-associated 1 (noal) mutant impaired in NO synthesis (Asai and Yoshioka 2009; Zeidler et al. 2004); the double mutant nial nia2 (nitrate reductase [NR]-null mutant impaired in both NRI and NR2 gene activities) (Bright et al. 2006; Desikan et al. 2004) for NO; rboh-D, rboh-F, and the double mutant rboh-D rboh-F (mutants affected in NADPH oxidases $[\mathrm{RBOH}]$ involved in ROS production in response to pathogen infection) (Torres et al. 2002); and $c s d 1$, csd2, and $f s d 1$ (mutants impaired in superoxide dismutases [SOD] CSD1, CSD2, and FSD1, respectively, involved in the scavenging of ROS) for ROS (Klibenstein et al. 1998; Torres et al. 2002). Although the single mutants behaved as the wild type, noal and the dou- ble mutants nial nia2 and rboh-D rboh-F showed an extremely susceptible phenotype (Fig. 6A and B). However, it should be noted that the NO-impaired mutants were even more susceptible than the susceptible ecotype Sha and that, among the ROS mutants, only the double mutant rboh- $D$ rboh- $F$ was impaired in its response to the fungus and exhibited a partially affected response. Consistent with these data, ROS production was strongly reduced in the mutant rboh-D $(60 \%)$, and almost totally abolished in rboh-D rboh-F (76\%) but not significantly affected in rboh-F (11\%) (Fig. 6C). NO synthesis was strongly reduced in noal (83\% inhibition) and also in nial nia2 $(62 \%$ inhibition) (Fig. 6C), suggesting that the two major pathways proposed for NO formation (reduction of nitrite to NO by nitrate reductase or oxidation of Arg to citrulline by NOS) might be involved in NO generation in response to S. sclerotiorum.
A

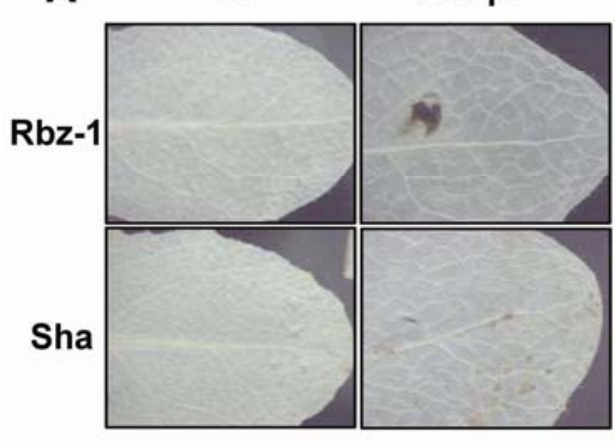

20 hpi

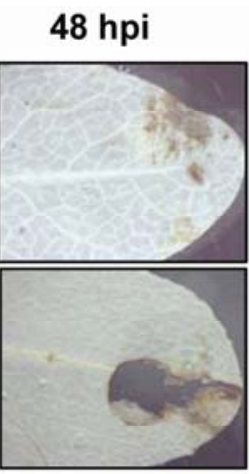

B

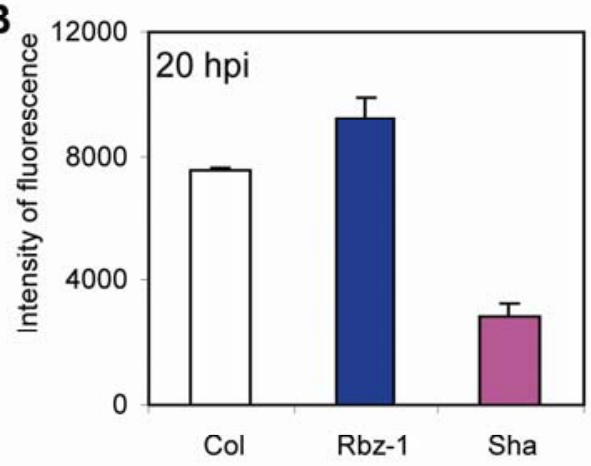

C

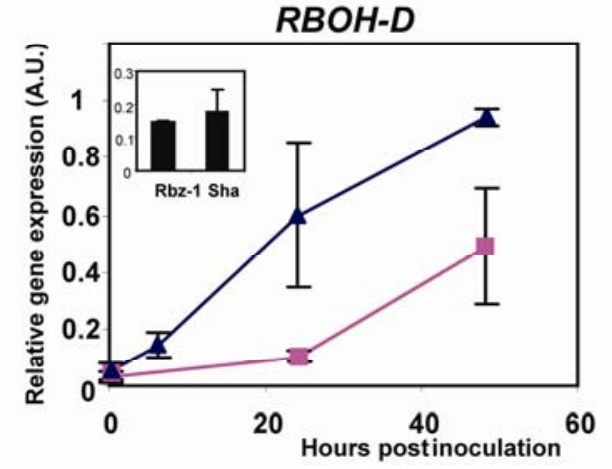

ni
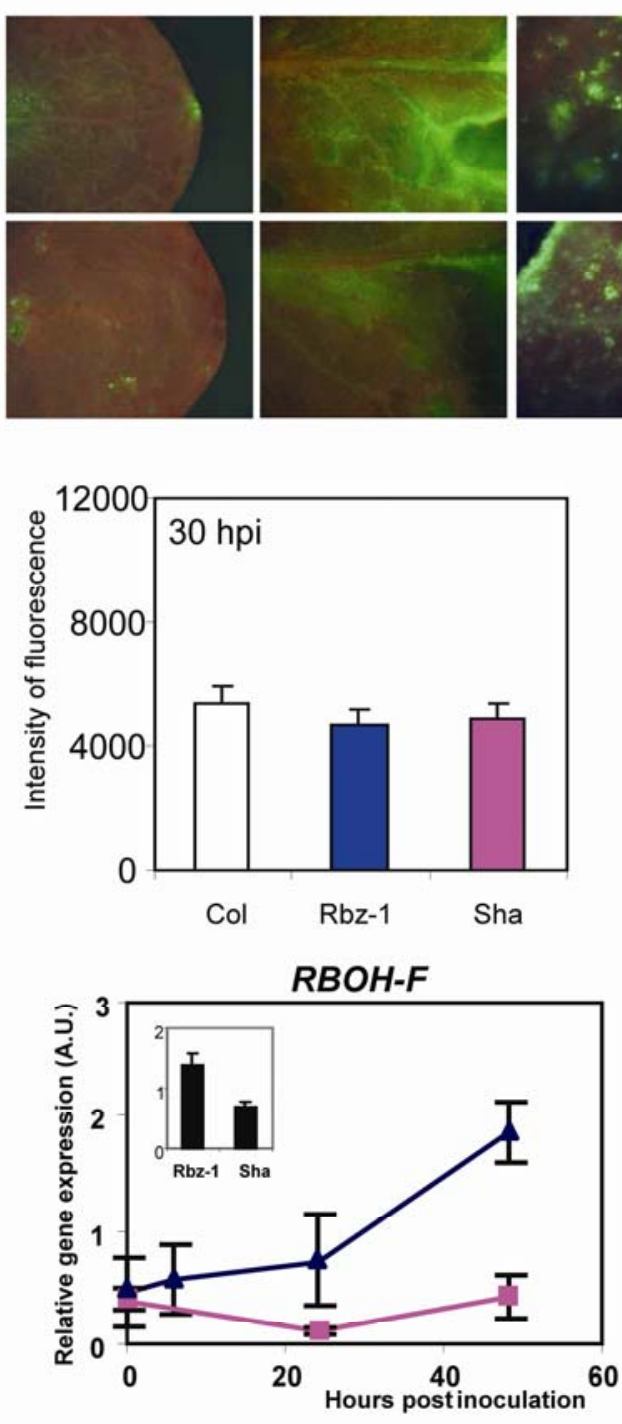

Fig. 4. Reactive oxygen species production $\left(\mathrm{H}_{2} \mathrm{O}_{2}\right)$ and expression of biosynthesis genes in susceptible and resistant ecotypes after inoculation with Sclerotinia sclerotiorum. A, Inoculated leaves of susceptible (Sha) and resistant (Rbz-1) ecotypes were taken from four independent plants at 20 and 48 h postinoculation (hpi) and were stained with 3,3'-diaminobenzidine (DAB) or $2^{\prime}, 7^{\prime}$-dichlorofluorescein diacetate $\left(\mathrm{H}_{2} \mathrm{DCF}\right.$-DA). Whole leaves were observed under a stereomicroscope for DAB staining (left panel) and under a fluorescence microscope (Leica MZ FLIII) for $\mathrm{H}_{2} \mathrm{O}_{2}$ staining using $\mathrm{H}_{2}$ DCF-DA (right panel) (ni, noninoculated). B, $\mathrm{H}_{2} \mathrm{O}_{2}$ production measured 20 and 30 hpi in leaf discs taken from the inoculated area (10 discs) or from noninoculated plants (5 discs) and fluorescence measured after $\mathrm{H}_{2}$ DCF-DA treatment. Data are means \pm standard deviation of 15 independent plants per experiment (four independent experiments). Fluorescence intensity in inoculated samples is expressed after deduction of fluorescence intensity of the corresponding noninoculated samples (varying from 1,900 to 2,900). C, Expression of $R B O H-D, R B O H-F$ genes in leaves of susceptible (Sha, pink) and resistant (Rbz-1, blue) ecotypes during the first 2 days after inoculation and $72 \mathrm{hpi}$ (box). Each measurement is an average of two replicates and experiments were repeated two times with similar results. Expression values of each gene were normalized using the expression level of $\beta$-tubulin 4 as an internal standard. Mean values and standard errors were calculated from two independent experiments. A.U., arbitrary units. 
All together, these results demonstrate that NO might have an important role in disease resistance to $S$. sclerotiorum.

To further analyze the role of ROS and NO in the activation of defenses to $S$. sclerotiorum, defense gene expression was evaluated in the nial nia2 and rboh-D rboh-F double mutants (Fig. 6D). In the double mutant nial nia2, expression of $P R 1$, $P D F 1-2$, and $A B I 1$ was found to be abolished or strongly reduced compared with the wild type, whereas VSP1 expression was delayed by $24 \mathrm{~h}$. In the rboh- $D$ rboh- $F$ double mutant, $P R 1$ expression was abolished, $P D F 1-2$ and $V S P 1$ expression was delayed, and $A B I I$ expression was upregulated. These results suggest a differential regulatory effect of $\mathrm{NO}$ and ROS on the different defense pathways. The loss of resistance observed in the NO mutants correlates with the downregulation of all defense markers tested, at least during the early stages of the interaction.

A

Rbz-1
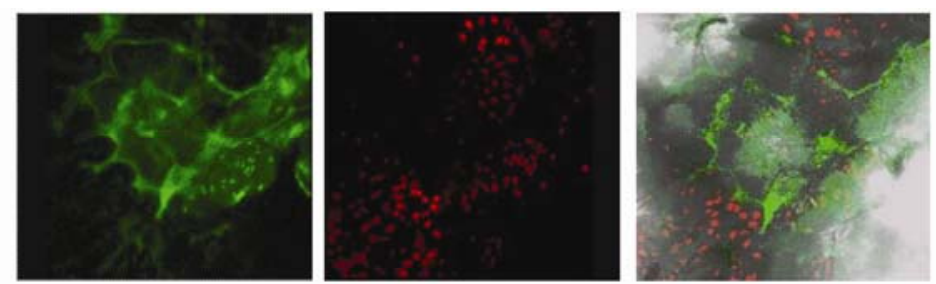

Sha
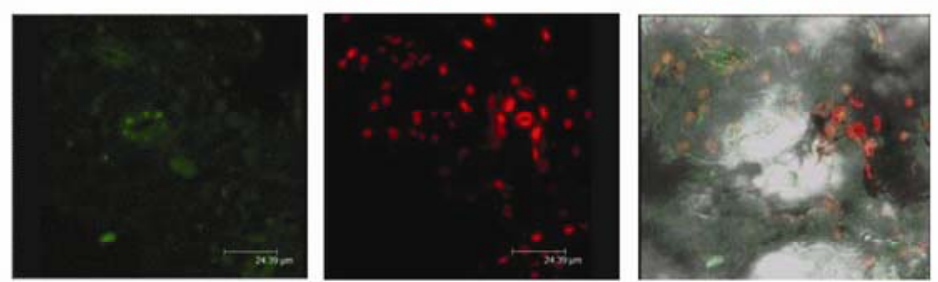

B
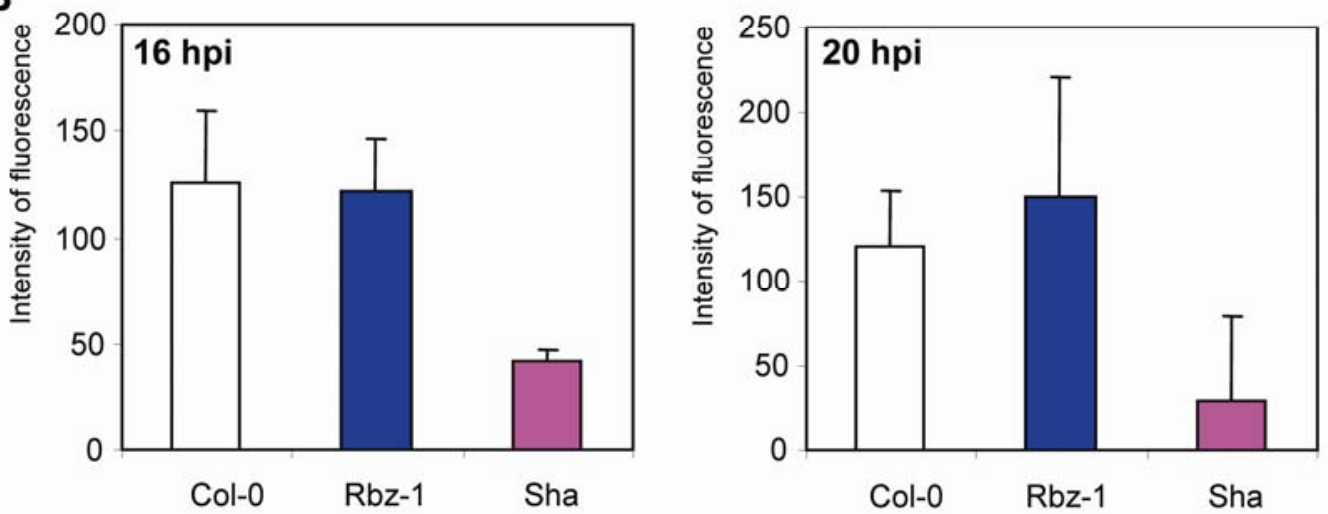

\section{C}

NIA1
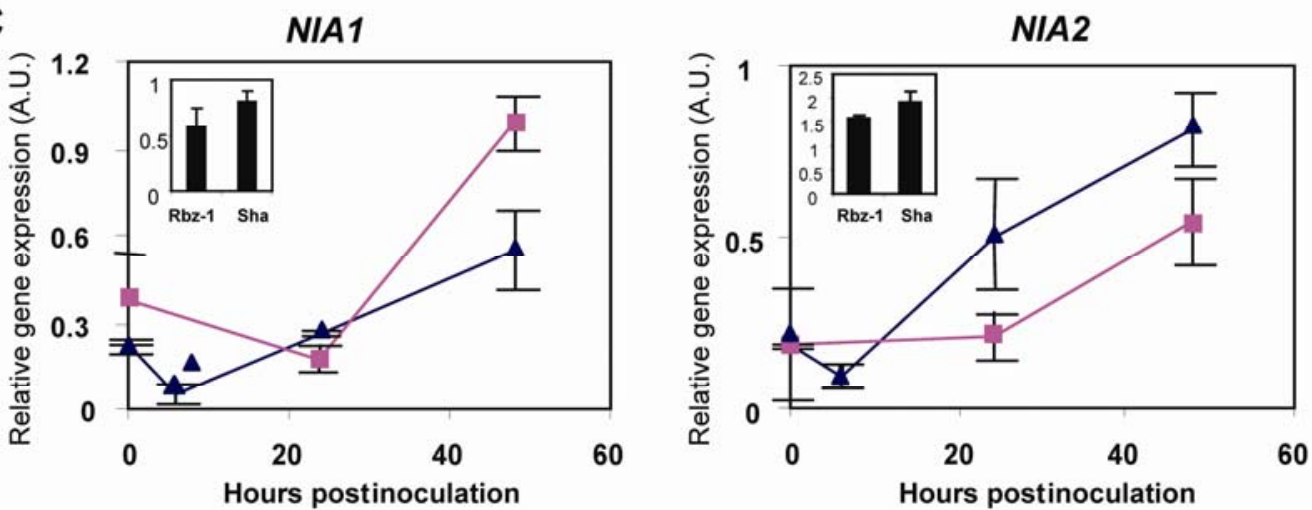

Fig. 5. Nitric oxide (NO) production and expression of biosynthesis genes in susceptible and resistant ecotypes after inoculation with Sclerotinia sclerotiorum. A, Leaves were infiltrated with 4,5-diaminofluorescein diacetate solution (10 $\mu \mathrm{M}) 16 \mathrm{~h}$ postinoculation (hpi) and observed with a confocal laser-scanning microscope. Samples were observed in fluorescence microscopy for detection of both diaminotriazolofluorescein (DAF-2T) fluorescence (green images) and autofluorescence (red images), and in bright-field microscopy. An overlay with fluorescence and bright field is presented in the right panels (gray images). For the susceptible ecotype, a long exposure was also applied to detect autofluorescence under the conditions used for detection of DAF-2T fluorescence. B, NO production was measured 16 and 20 hpi. Leaf discs were taken from the inoculated area (10 discs) or from noninoculated plants $\left(5\right.$ discs) and increase of fluorescence was measured after $2^{\prime}, 7^{\prime}$-dichlorofluorescein diacetate $\left(\mathrm{H}_{2} \mathrm{DCF}\right.$-DA) treatment. Data are means \pm standard deviation of 15 independent plants per experiment (four independent experiments). Fluorescence intensity in inoculated samples is expressed after deduction of fluorescence intensity of the corresponding noninoculated samples (varying from 35 to 46). C, Expression of NIA1 and NIA2 genes in leaves of susceptible (Sha, pink) and resistant (Rbz-1, blue) ecotypes during the first 2 days after inoculation and 72 hpi (box). Each measurement is an average of two replicates and experiments were repeated two times with similar results. Expression values of each gene were normalized using the expression level of $\beta$ tubulin4 as an internal standard. Mean values and standard errors were calculated from two independent experiments. A.U., arbitrary units. 
Defense gene expression

in the oilseed rape-S. sclerotiorum interaction.

S. sclerotiorum causes a highly destructive disease in oilseed rape that results in important economic losses. Studies on the
A. thaliana model allowed the molecular characterization of the plant response to the fungal pathogen in this work and others. Thus, analysis of gene expression in the context of the cropfungus interaction would give some interesting clues about

A
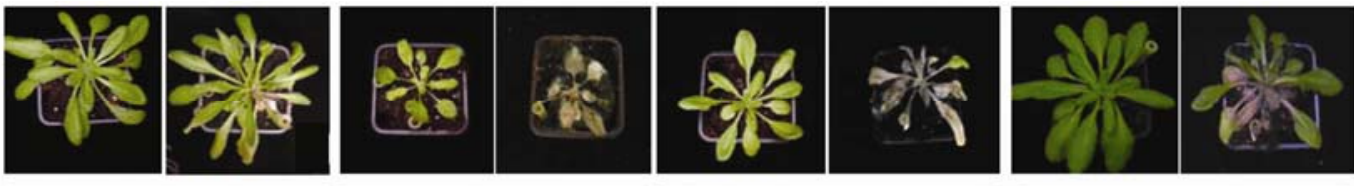

Col-0

noa1

nia1 nia2

rboh-D/rboh-F

B
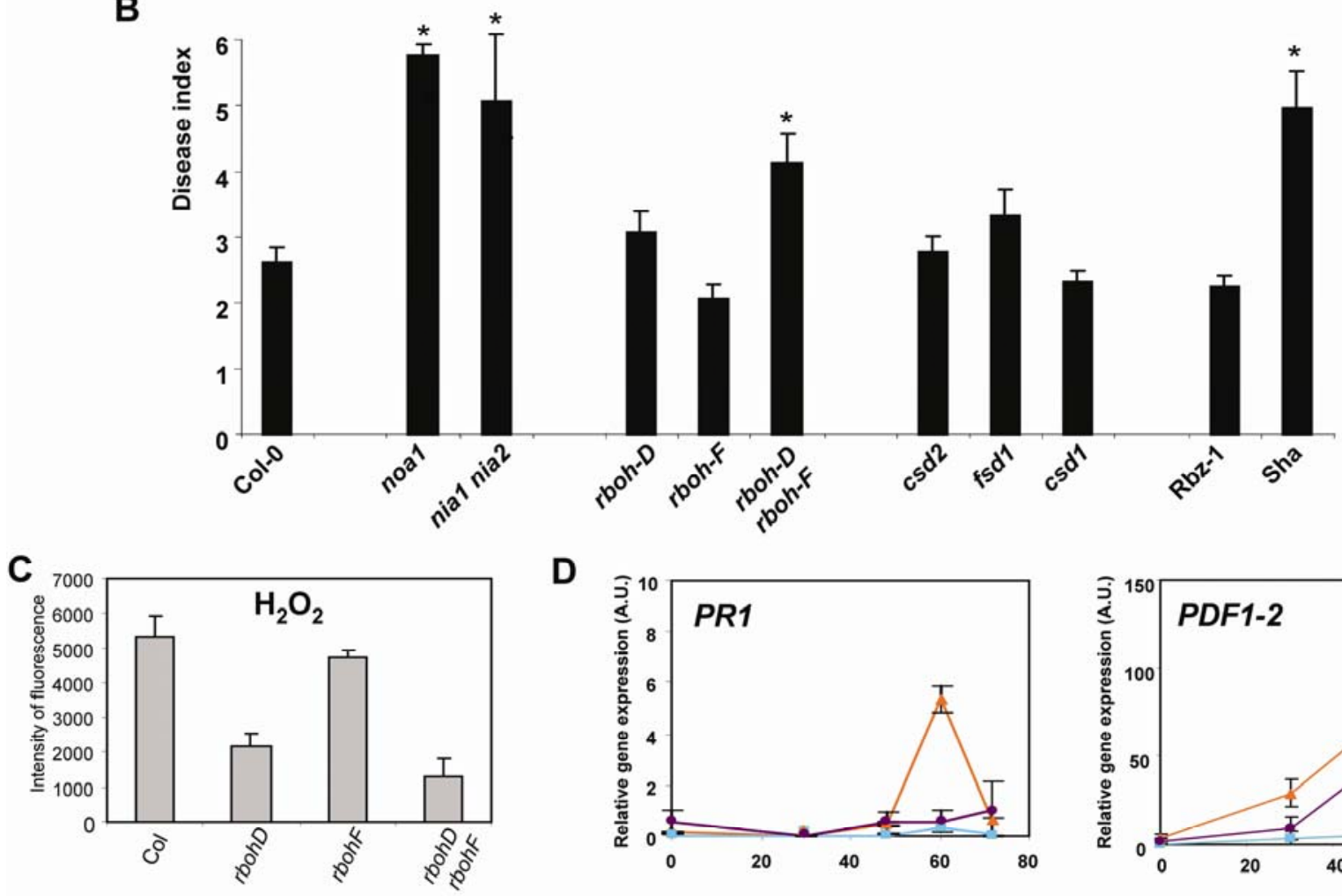

D
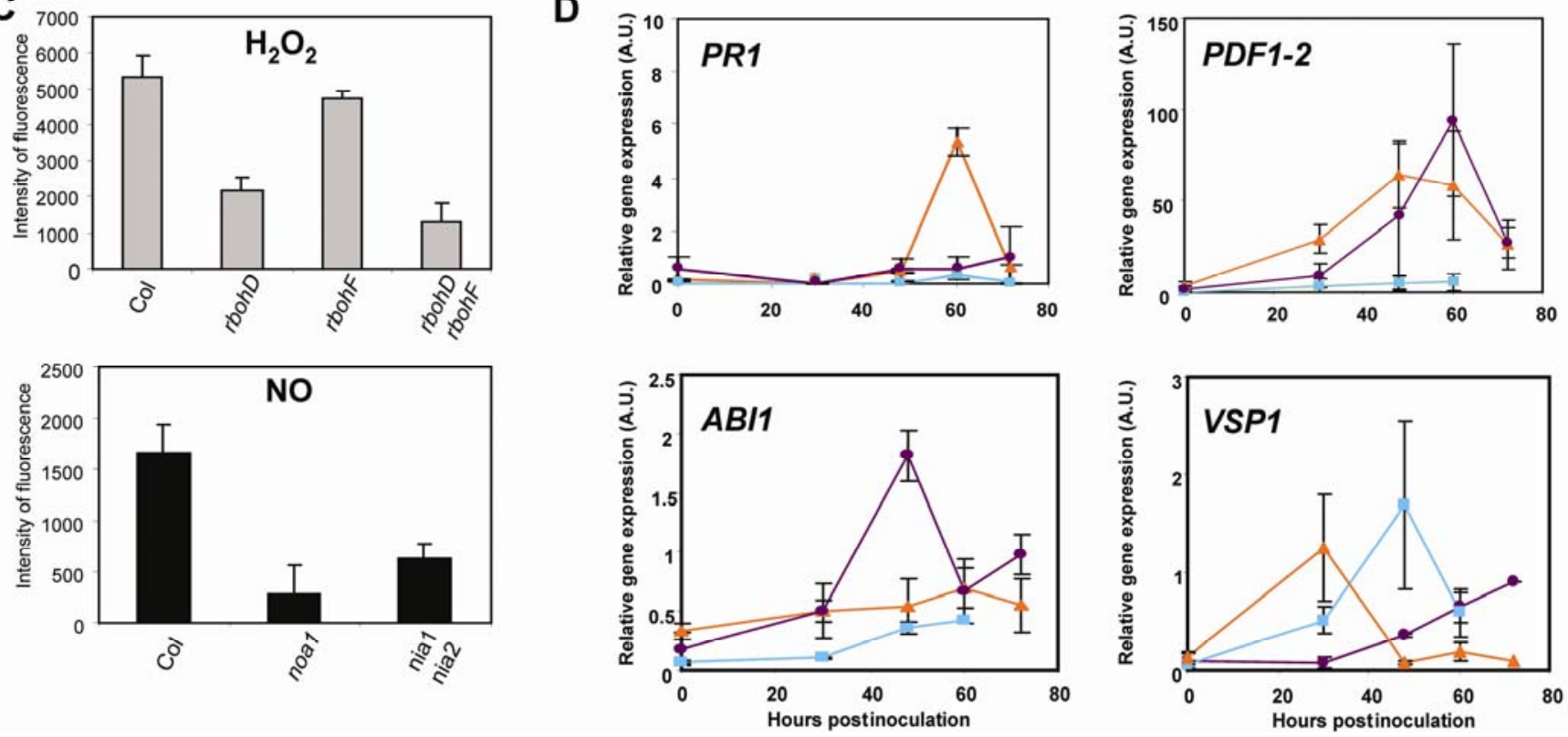

Fig. 6. Effect of mutations affecting reactive oxygen species (ROS) and nitric oxide (NO) production and signaling pathways on resistance to Sclerotinia sclerotiorum. Leaves of 4-week-old plants were inoculated with S. sclerotiorum (strain S55) and disease index was evaluated 7 days postinoculation. A, Symptoms of mutant and wild-type plants: 4-week-old plants inoculated with S. sclerotiorum (plant on the right) or healthy (plant on the left). B, Disease scores of noal and nial nia2 mutants for the NO pathway and $r b o h-D, r b o h-F, r b o h-D$ rboh-F, csd2, fsdl, and $c s d l$ for the ROS pathway were evaluated 7 days after inoculation compared with the wild-type ecotypes Col-0 (genetic background of the mutants), Rbz-1 (resistant ecotype), and Sha (susceptible ecotype). Means and standard deviation were calculated from scoring at least six plants. A significant difference in susceptibility for a mutant compared with the wild-type Col-0 is indicated with an asterisk $(P<0.05)$. C, ROS and NO production in mutant plants $r b o h-D$, rboh- $F$, rboh-D rboh- $F$, noal, and nial nia2. $\mathrm{H}_{2} \mathrm{O}_{2}$ production was measured $30 \mathrm{~h}$ postinoculation (hpi). Inhibition of $\mathrm{H}_{2} \mathrm{O}_{2}$ production compared with the wild-type Col- 0 in $r b o h-D$, rboh- $F$, and $r b o h-D$ rboh-F mutants was 60,11 , and $76 \%$, respectively. NO production was measured at 16 hpi. Inhibition of NO production compared with the wild-type Col-0 in noal and nial nia2 mutants was 83 and 62\%, respectively. Inoculated and noninoculated leaves of the different mutants were taken from four independent plants and the experiment was repeated twice, with similar results. D, Defense gene expression in the wild-type ecotype (Col-0) (orange), nia1 nia2 double mutant (blue), and rboh-D rboh-F double mutant (purple) after inoculation with S. sclerotiorum. Leaves of 4-week-old plants were inoculated with $S$. sclerotiorum (strain S55) and harvested at different time points after inoculation. Transcript levels of defense genes were evaluated by quantitative reverse-transcription polymerase chain reaction. Each measurement is an average of two replicates and experiments were repeated two times with similar results. Expression values of each gene were normalized using the expression level of $\beta$-tubulin 4 as an internal standard. Mean values and standard errors were calculated from two independent experiments. A.U., arbitrary units. 
whether the regulation of defense is conserved. Thus, marker genes for SA, JA, ET, and ABA pathways were tested in two resistant lines (Norin 9 and Z821) and a susceptible one (Cheyenne) (Fig. 7). As in Arabidopsis, PRl, NIA1, and $R B O H-D$ were expressed at higher levels in the resistant lines compared with the susceptible ones. $R D-20$, a marker of the ABA pathway, was not differentially expressed during the

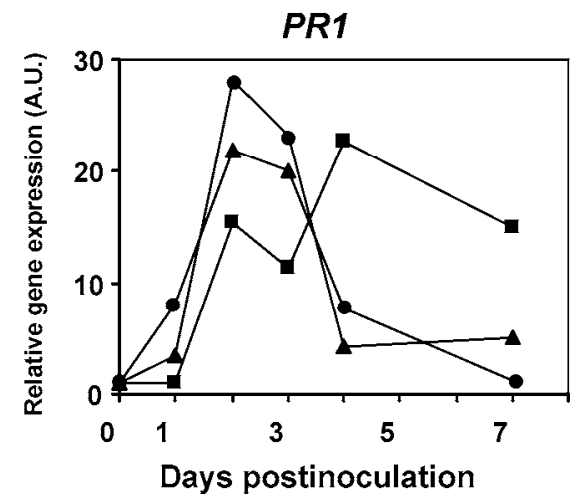

NIA1

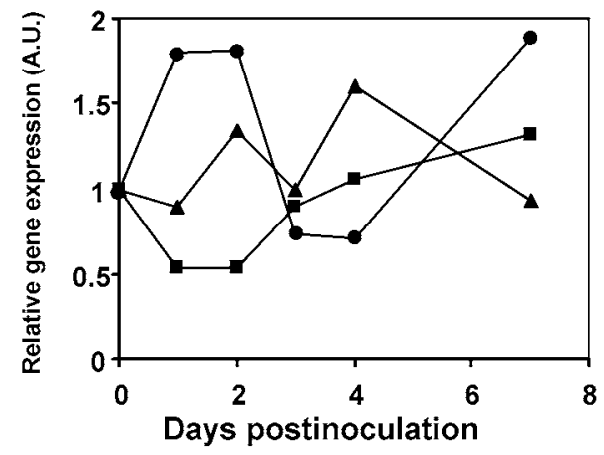

WRKY70
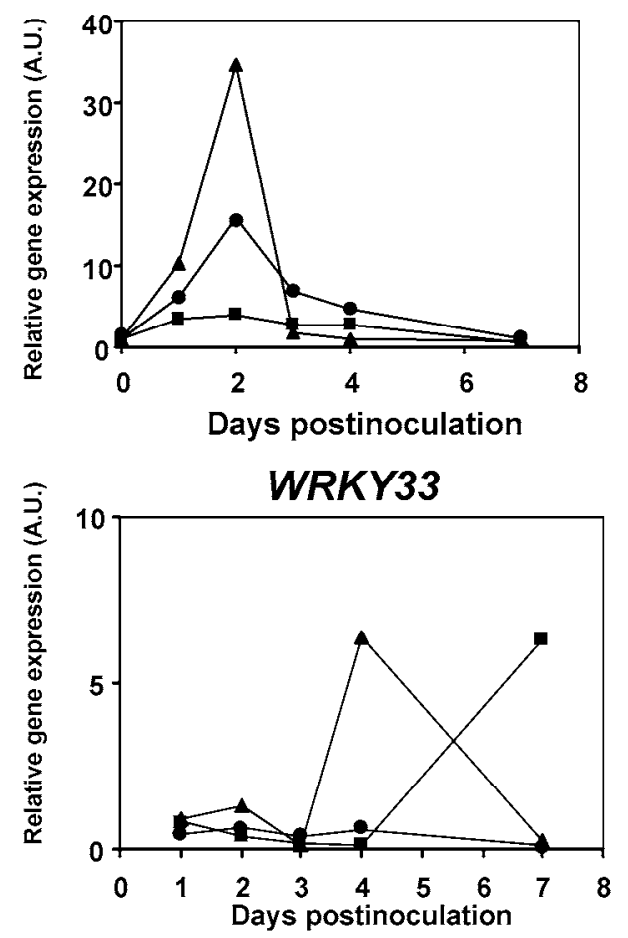

early stages of infection in the different lines and was associated with disease in the later stages. WRKY33 and 40 exhibited similar profiles in oilseed rape and Arabidopsis (i.e., induced at higher levels in the resistant lines). Surprisingly, WRKY70 and $M P K 4$, both involved in the repression of SA signaling (Andreasson et al. 2005; Li et al. 2004), showed opposite regulation profiles, WRKY7O being upregulated at higher levels in
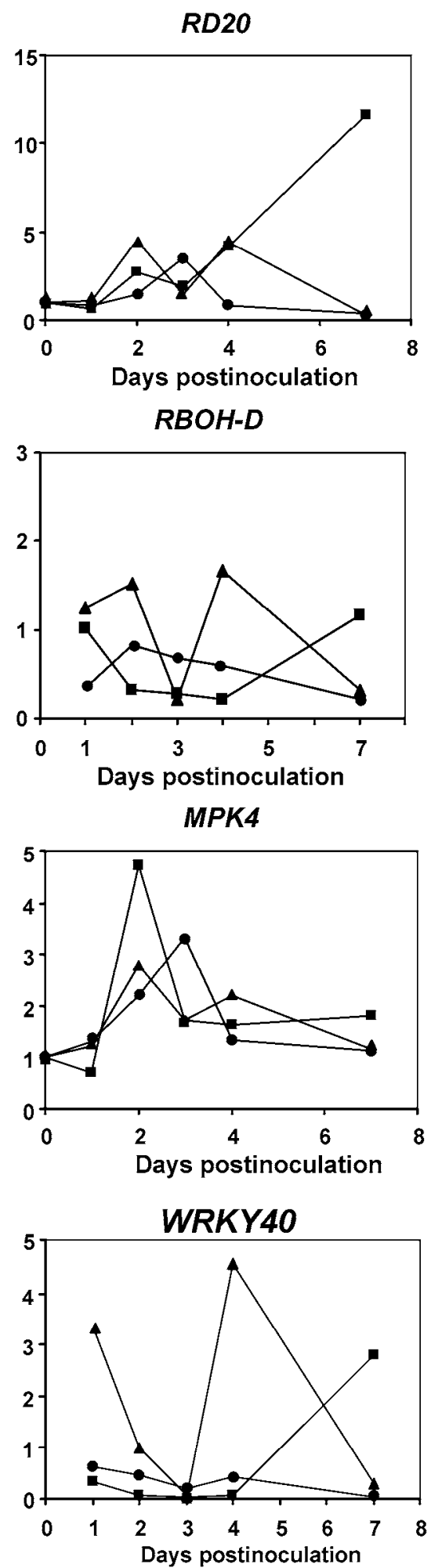

Fig. 7. Gene expression analysis in oilseed rape leaves after inoculation with Sclerotinia sclerotiorum. Four-week-old plants were inoculated with $S$. sclerotiorum (strain S55) and harvested at different times after inoculation. Three lines were used: two resistant lines, Norin-9 (triangles) and Z821 (circles), and one susceptible line (squares), Cheyenne. Transcript levels of defense genes were evaluated by quantitative reverse-transcription polymerase chain reaction. Each biological condition was represented by three biological replicates. 
the resistant lines and $M P K 4$ being induced whatever the line. However, it should be noted that MPK4 was downregulated at the very early stages of the interaction in the susceptible line whereas it was induced in the resistant lines (Fig. 7). This is in good agreement with the recently proposed role of MPK4 as a positive regulator of JA-mediated defense in response to $S$. sclerotiorum (Wang et al. 2009).

\section{DISCUSSION}

Previous studies of the interaction Arabidopsis-S. sclerotiorum suggested that the extreme susceptibility of the host prevents the phenotypical and molecular characterization of this interaction. Here, by analyzing the natural variation of resistance to $S$. sclerotiorum, we showed that some ecotypes such as Ws-4, Rbz-1, or Col-0 display a fairly high level of resistance to the fungus while ecotypes such as Sha, Ita-0, or Cvi-0 are highly susceptible. A large number of ecotypes exhibited intermediary phenotypes, revealing the existence of quantitative resistance in Arabidopsis, as already found in crops. At this point, it should be noted that the Col-0 ecotype previously estimated as extremely susceptible to $S$. sclerotiorum clearly displays a high level of resistance compared with other ecotypes, in our tests and in response to a natural strain of $S$. sclerotiorum.

Consequently, this study allowed us to investigate the molecular determinants of resistance and defense in the genetic backgrounds Col-0 and Ws-4, the ecotypes mostly used in mutational approaches. The most important finding of this study was the discovery of the role of NO and ROS in the interaction. In addition, the role of other signaling pathways such as ET, SA, JA, and ABA was thoroughly evaluated, together with other pathways, showing that the responses already characterized for necrotrophic fungi are operating for S. sclerotiorum.

\section{Role of ABA in resistance to $S$. sclerotiorum.}

The plant hormone ABA plays important roles in disease resistance but its precise function remains unclear. Although several reports have indicated a negative effect of ABA on resistance to different pathogens, others have suggested a positive role of this hormone (Mauch-Mani and Mauch 2005). The role of ABA seems to depend not only on the pathogen's lifestyle but also on the specific interaction (Adie et al. 2007). For example, an increase in ABA levels was observed in response to some pathogens (Adie et al. 2007; Kaliff et al. 2007; Whenham et al. 1986), whereas ABA accumulation has been reported to be downregulated by Alternaria brassicicola (Flors et al. 2005). ABA biosynthesis and signaling pathways may also be targeted by pathogens to suppress the plant defense response. This has been demonstrated for example for Pseudomonas syringae type III secretion system effectors (de TorresZabala et al. 2007). In the case of S. sclerotiorum, ABA-deficient mutants have been reported to be more susceptible to pathogen infection (Guimaraes and Stotz 2004), and the regulation of guard cells was found to be a major mechanism of resistance in this interaction. These and other reports suggest that ABA would affect pathogen resistance via a complex interplay of mechanisms, possibly including callose deposition or interference with SA, JA, and ET signaling (Adie et al. 2007; Flors et al. 2005; Kaliff et al. 2007; Mauch-Mani and Mauch 2005). An interesting finding indicates that ABA is required for JA biosynthesis and JA-dependent defense gene expression in response to infection with Pythium spp. another necrotrophic pathogen (Adie et al. 2007). In our hands, ABAdeficient and insensitive mutants in the Ler-0 background (aba3-2, abil-1, and abi2-1) displayed a complete loss of resistance to $S$. sclerotiorum. In contrast, ABA mutants in the
Col-0 background (aba3-1, abi4-101, abi4-103, and abi5) behaved like the wild type, with the exception of aba2-3, which was slightly more susceptible than the wild type. These results are in good agreement with previous observations made in the context of the interaction Arabidopsis-Leptosphaeria maculans, which showed that the higher levels of camalexin produced by Col-0 compared with Ler- 0 could interfere with susceptibility or resistance assessments (Kaliff et al. 2007). Another nonexclusive interpretation of our data is based on the strength of the mutations, with mutants strongly affected in ABA biosynthesis (aba2-3 and aba3-2) or mutants with complete ABA insensitivity (abil and abi2) being susceptible and the others (abi4 and abi5) being not significantly affected in their response to Sclerotinia spp. However, we observed differential phenotypes for two strong alleles of $a b a 3$ in the two genetic backgrounds (not significantly different from the wild type in Col background and highly susceptible in the Ler background), suggesting that both parameters (mutation strength and genetic background) may influence the resistance response to S. sclerotiorum. We were also unable to measure detectable amounts of ABA in infected leaves (data not shown), suggesting that ABA induction is rather limited in the context of this interaction. We did not observe a higher susceptibility of abi4 (Col-0) (although we tested two independent mutant lines) or a wildtype phenotype for abi2-1 (Ler-0) as previously observed by Stotz and collaborators (Guimaraes and Stotz 2004). This could be due to the inoculation conditions or the fungal strain used. In conclusion, ABA production appears to be essential for resistance to $S$. sclerotiorum, whereas the importance of ABA signaling components seems to depend on the genetic background and might be compensated by other defense mechanisms, such as phytoalexins.

\section{Role of JA in resistance to $S$. sclerotiorum.}

The three phytohormones SA, JA, and ET have been shown to play major roles in the regulation of the signaling pathways leading to defense, through a complex regulatory network involving positive and negative crosstalk between each pathway, in order to fine tune the defense response to each pathogen. It is generally accepted that JA and ET are more often associated with resistance to necrotrophic pathogens (Rojo et al. 2003; Lorenzo and Solano 2005) while SA has a central role in response to biotrophic pathogens. In the context of the Arabidopsis-S. sclerotiorum interaction, we quantified SA, JA, and ET production and showed that the three hormones are induced differentially in the resistant and susceptible ecotypes (data not shown), in good agreement with the reported expression of marker genes (Fig. 3).

Here, by using three different mutants or transgenic lines impaired in SA production (sid1/eds5, sid2/eds16, and nahG) and one impaired in SA signaling (nprl-1), we clearly demonstrate that resistance to $S$. sclerotiorum is not dependent on SA. In contrast, as previously shown, the JA-insensitive mutant coil-1 was found to be highly susceptible to S. sclerotiorum (Guo and Stotz 2007), suggesting a major role for JA. However, if the jasmonate-signaling cascade seems to be essential for resistance to $S$. sclerotiorum, including at least COI1 and probably other downstream components, jarl-1 showed a completely wild-type phenotype in response to $S$. sclerotiorum. This suggests that the availability of bioactive jasmonates is not essential for resistance to $S$. sclerotiorum or that possible crosstalk between jasmonate signaling and other regulatory pathways is likely to play a role in resistance to $S$. sclerotiorum. The ET pathway does not seem to play a predominant role in resistance to $S$. sclerotiorum, because only two mutants (ein2-1 and eto3) out of seven displayed some alterations, which are quantitatively less important than in the case of coil-1. The 
fact that eto 2 and eto3 mutations, which both alter the C-terminal domain of ACS (ACS5 and ACS9, respectively), and the mechanisms that target ACS for proteolysis (Chae et al. 2003) confer different phenotypes in response to infection suggests a differential implication of these enzymes in response to $S$. sclerotiorum. In favor of a major role of JA in this interaction, is the recent discovery that overexpression of Brassica napus MPK4 enhances resistance to $S$. sclerotiorum in oilseed rape (Wang et al. 2009). MPK4 was the first gene to be identified as a regulator of the negative crosstalk between JA and SA in the activation of defenses (Petersen et al. 2000).

\section{Role of ROS and cell death pathways.}

Modulation of ROS signaling by the reactive oxygen gene network is performed in plants by production and scavenging, through at least 150 genes (Mittler et al. 2004). Key components of this network have been identified by genetic approaches. For example, the absence of NADPH oxidase genes $A t R B O H-D$ and $A t R B O H-F$ suppresses ROS production and some defense responses (Torres et al. 2002). In the case of the interaction Arabidopsis-S. sclerotiorum, the absence of these two genes also leads to suppression of ROS generation and decreased resistance. However, depletion in the levels of three SOD (CSD1, CSD2, and FSD1, involved in ROS scavenging) in the mutants $c s d 1, c s d 2$, and $f s d 1$, respectively, does not affect resistance to the fungus. The high number of enzymes involved in ROS detoxification suggests redundancy and can explain this result. Another (nonexclusive) possibility might be that the ROS signal pathway only accompanies and regulates the major pathways involved in $S$. sclerotiorum resistance but does not exert a crucial function. In favor of this hypothesis, i) defense marker genes are only quantitatively affected (with the exception of PRl, whose expression is abolished) in the rboh$D$ rboh-F double mutant and ii) absence of NPR1, a redoxsensitive regulator of the SA pathway, does not affect resistance to S. sclerotiorum. In contrast, regulation of cell death appeared to be critical for the interaction: the cell death mutants $r c d 1-1, h l m 1-1$, and vadl-1 were clearly impaired in resistance to $S$. sclerotiorum. Oxalic acid, a major pathogenicity factor of the fungus, is an elicitor of programmed cell death and ROS production (Guo and Stotz 2007; Kim et al. 2008). These observations are in good agreement with the observation that the hypersensitive cell death program facilitates plant infection by necrotrophic pathogens such as Botrytis cinerea (Govrin and Levine 2000).

\section{NO is a key component}

of resistance or defense to $S$. sclerotiorum.

NO, like ROS, is an important signaling molecule that is rapidly generated after recognition of pathogens (Wendehenne et al. 2004). However, its exact function remains poorly documented. In the context of plant-pathogen interactions, NO is involved in the modulation of SA, JA, and ET synthesis and possibly other mechanisms in plants (Delledone 2005; Huang et al. 2002; Parani et al. 2004). It has also been reported that $\mathrm{H}_{2} \mathrm{O}_{2}$ acts together with NO during programmed cell death (Zago et al. 2006). Thus, NO appears as an early signaling component, possibly orchestrating a number of downstream signaling pathways. In the context of the Arabidopsis-S. sclerotiorum interaction, we show here that NO is rapidly generated during the early stages of the interaction in the resistant ecotype and at later times in the susceptible ecotype. Specificity of DAF-2DA used here for detection of $\mathrm{NO}$ has been previously demonstrated (Besson-Bard et al. 2008). Direct measurement of free extracellular NO would offer important new insights into its role in plants infected with pathogens (Besson-Bard et al. 2008) but requires electron paramagnetic resonance spectroscopy (not available for our experi- ments). This production coincides with induced expression of NO biosynthesis genes (NIAl and 2). In fact, two pathways might exist in plants for NO synthesis: the first pathway involves cytosolic nitrate reductases (NR) (Yamasaki and Sakihama 2000) and the second would implicate a putative plant NOS-like enzyme, although no homolog of animal NOS has been found in the genome of Arabidopsis (Besson-Bard et al. 2008). The role of NR as a NO source in plants is supported by the abolition of NO production and stomatal closure in the Arabidopsis nial nia2 NR-deficient mutant, in response to ABA (Bright et al. 2006; Desikan et al. 2001). On the other hand, the Arabidopsis noal mutant that we used in this study shows reduced levels of NO (Zeidler et al. 2004). This mutant was previously thought to be impaired in AtNOS1. However, it has recently been suggested that AtNOA1 might encode a mitochondrial GTPase, with NO production being affected in the mutant as a secondary effect of the mutation (Besson-Bard et al. 2008; Flores-Pérez et al. 2008). Other reports suggest that AtNOA1 indirectly participates in Arg-dependent NOS activity in plants (Asai et al. 2008; Zhao et al. 2007). We cannot rule out the hypothesis that the reduced NO levels measured in this mutant are related to a reduced LArg level (Modolo et al. 2006) and, therefore, to a lack of substrate to produce NO from the L-Arg pathways. This mutant constitutes an interesting tool for the study of the role of $\mathrm{NO}$ because of its reduced levels of NO. In this work, we clearly show that the double mutant nial nia2 and the mutant noal are both affected in their ability to produce NO after fungal inoculation and are extremely susceptible to $S$. sclerotiorum. Furthermore, expression of all the defense marker genes tested is abolished (or delayed) in the double mutant. To our knowledge, this is the first genetic demonstration of the role of NO in disease resistance to necrotrophic pathogens. A very recent report supports this conclusion by demonstrating that NO participates, in collaboration with ROS, in resistance to B. cinerea in Nicotiana benthamiana (Asai and Yoshioka 2009). Moreover, it was also shown that silencing of NOAl in N. benthamiana compromised INF1 elicitin-induced NO production and altered tobacco resistance to $B$. cinerea. In our study, the mammalian NOS inhibitor L-NAME partially suppressed NO production (37\% inhibition; data not shown), in agreement with the reduction of NO generation in the inoculated noal mutant, which is also not complete. These results, together with the fact that NO synthesis was also affected in the double mutant nial nia2, indicate that the two pathways (NR and NOS) possibly constitute a source of NO in $S$. sclerotiorum-infected plants. The major role of NO in resistance to S. sclerotiorum can be interpreted in different ways: i) as a regulatory function (in this work and by others) of defense gene expression, ii) via interference with the ROS signaling pathway, or iii) via modulation of cell death. Although our work provides some clues for these different roles, further experiments must be carried out to fully investigate the role of NO as a signal inducer and gene expression modulator in the context of plant-pathogen interactions.

\section{Gene expression profiles in response to $S$. sclerotiorum are similar in Arabidopsis thaliana and Brassica napus.}

$S$. sclerotiorum causes considerable damage in oilseed rape, which is one of the most important oil crops in the world. Oilseed rape is also phylogenetically very close to Arabidopsis. Analysis of gene expression profiles in Brassica napus in response to $S$. sclerotiorum indicated induction of JA-, ET-, and ROS-associated genes in good agreement with our findings in Arabidopsis but did not reveal the major role of NO (Yang et al. 2007; Zhao et al. 2006b). These genome-wide analyses have not yet been performed in Arabidopsis and, therefore, comparisons with expression profiles in this model plant cannot be made. Here, a compared expression analysis focused 
on several defense-signaling marker genes and some transcriptional regulators involved in the integration of these pathways and revealed a good conservation of gene regulation in response to $S$. sclerotiorum in both hosts. For these studies, we used two lines of oilseed rape, Norin-9 and Z821, which show partial resistance to $S$. sclerotiorum. Indeed, several quantitative trait loci were detected in different populations (Bert et al. 2002; Liu et al. 2005; Zhao and Meng 2003; Zhao et al. 2006a) involved in leaf resistance at the seedling stage (such as Z821) or in stem resistance in mature plants (such as Norin-9) (unpublished data). In accordance with these phenotypes, expression of NIA-2 was higher in leaves of the line Z821 (Fig. 7). High expression levels for the other genes (WRKY70, 33, 40, PR1, and $R B O H-D$ ) were also found in Norin-9. Surprisingly, $R D 20$ expression was not differentially regulated in the different lines. These results show a fairly good conservation of gene regulation in response to $S$. sclerotiorum in oilseed rape and Arabidopsis. They also suggest an essential role for NO, which seems to represent a precise marker of resistance in oilseed rape. These findings open the way to a comprehensive study of the molecular mechanisms operating during establishment of resistance in oilseed rape in response to $S$. sclerotiorum.

In summary, our study shows that resistance to $S$. sclerotiorum in Arabidopsis is quantitative and dependent on a complex defense signaling network. We propose that it is primarily controlled by the signaling molecule NO, and by the JA/ET pathways, as in the case of the response to other necrotrophic fungi. These findings constitute the basis for analysis of the molecular mechanisms underlying the function of NO in resistance to $S$. sclerotiorum and also to different necrotrophic pathogens, as suggested by recent reports.

\section{MATERIALS AND METHODS}

\section{Plant materials and growth conditions.}

Experiments were performed using Arabidopsis thaliana (Columbia, Ler-0, and Ws-4 ecotypes, and the ecotypes mentioned in Figure 1) wild type. For analysis of natural variation, the core collection from the Institut National de la Recherche Agronomique (INRA) VNAT webservice was used. The different mutants which were used in this study are described in Table 1 . Other ecotypes and some of the mutants used came from the SALK collection ( $c s d 1, \operatorname{csd} 2$, and $f s d 1$ ). Plants were grown as previously described (Bouchez et al. 2007).

For B. napus, experiments were performed using the genotypes Norin-9, Z821, and Cheyenne. Plants were grown in a growth chamber at $22^{\circ} \mathrm{C}$ during the day $\left( \pm 2^{\circ} \mathrm{C}\right)$ and $18^{\circ} \mathrm{C}$ during the night $\left( \pm 2^{\circ} \mathrm{C}\right)$, with a 16 -h light period and a light intensity of $280 \mu \mathrm{mol} / \mathrm{m}^{2} / \mathrm{s}$.

\section{Fungal strain and plant inoculation procedures.}

The mycelium of $S$. sclerotiorum (S55 strain) was grown at $25^{\circ} \mathrm{C}$ on paper discs previously saturated with potato-dextrose broth medium. To control the inoculum and ensure equal infection, i) the fungal strain was grown from a sclerotium for each inoculation assay (this avoids any loss of aggressiveness) and ii) the discs, with standardized size and volume, were placed on the petri dish, at the border of a growing colony, in order to get hypha of the same age. The disc covered with mycelium represents a standardized inoculum in terms of quantity and aggressiveness. Four-week-old plants were inoculated with such a disc covered by mycelium and applied on one leaf of each plant. Plant inoculations were performed under greenhouse conditions. The trays containing the inoculated plants were saturated with humidity for the first 48 hpi. Each mutant and ecotype was evaluated in a complete randomized block design. Three plants of each mutant or ecotype per block, with at least two blocks per experiment, were evaluated for resistance to $S$. sclerotiorum. These plants were distributed randomly in several trays. Two to four independent experiments were performed for each ecotype or mutant. Each inoculated plant was scored every 2 days, from 2 to $14 \mathrm{dpi}$, as no symptom $=0$, necrosis just around the disk $=0.2$, half of the leaf necrotized $=$ 0.5 , inoculated leaf necrotized $=1$, inoculated leaf and petiole necrotized $=1.5$, symptoms observed on leaves just beside the inoculated leaf $=2$, symptoms observed on one-third of the rosette leaves $=3$, symptoms observed for more than half of the leaves $=4$, symptoms observed for all the leaves of the rosette (beyond the petioles) $=5$, and plant dead $=6$.

For B. napus, the same strain of S. sclerotiorum (S55) and the same conditions were used, with the exception that a disk of mycelium was applied on the middle of the leaf.

\section{Statistical analyses of Sclerotinia sclerotiorum scores.}

Data were analyzed for each experiment, and adjusted means of disease scores (lsmeans) of mutants and ecotypes were estimated from variance analysis. Data analyses were performed with the Statistical Analysis System (SAS) software (SAS Institute Inc., Cary, NC, U.S.A.). Variance analysis of disease scores was performed using PROC GLM of SAS.

\section{RNA extraction and quantitative reverse-transcription polymerase chain reaction analysis.}

For Arabidopsis material, RNA extraction, reverse transcription (RT), and quantitative polymerase chain reaction (Q-PCR) were performed according to manufacturer's recommendations (Macherey-Nagel, Hoerdt, France and Roche Diagnostics, Meylan, France), as previously described by Bouchez and associates (2007) (Supplementary Table 1). $\beta$-Tubulin4 and a gene (At2g28290) were used as controls.

Table 1. Arabidopsis mutants used in this study

\begin{tabular}{|c|c|c|c|}
\hline $\begin{array}{l}\text { Signaling } \\
\text { pathway }\end{array}$ & $\begin{array}{l}\text { Mutants } \\
\text { or lines }\end{array}$ & $\begin{array}{c}\text { Genetic } \\
\text { background }\end{array}$ & References \\
\hline \multirow[t]{3}{*}{$\begin{array}{l}\text { Early resistance } \\
\text { components }\end{array}$} & $n d r 1-1$ & Col-0 & Century et al. 1995 \\
\hline & eds1 & Ws-0 & Parker et al. 1996 \\
\hline & pad4 & Col-0 & Glazebrook et al. 1996 \\
\hline \multirow[t]{4}{*}{ Salicylic acid } & sidl/eds 5 & Col- 0 & $\begin{array}{l}\text { Rogers and Ausubel } \\
1997\end{array}$ \\
\hline & sid2/eds 16 & Col- 0 & Wildermuth et al. 2001 \\
\hline & nprl-1 & Col-0 & Cao et al. 1994 \\
\hline & $n a h G$ & Col-0 & Friedrich et al. 1995 \\
\hline \multirow[t]{6}{*}{ Ethylene } & ein2-1 & Col-0 & $\begin{array}{l}\text { Guzman and Ecker } \\
1990\end{array}$ \\
\hline & ein3-1 & Col-0 & Chao et al. 1997 \\
\hline & $\operatorname{ein} 4-1, \operatorname{ein} 7$ & Col-0 & Roman et al. 1995 \\
\hline & eto $2-1$ & Col-0 & Vogel et al. 1998 \\
\hline & eto3 & Col-0 & Woeste et al. 1999 \\
\hline & oxerf1 & Col-0 & Lorenzo et al. 2003 \\
\hline \multirow[t]{2}{*}{ Jasmonic acid } & jarl-1 & Col-0 & Staswick et al. 1992 \\
\hline & coil-1 & Col-0 & Feys et al. 1994 \\
\hline \multirow[t]{5}{*}{ Abcisic acid } & $a b a 2-3, a b a 3-1$ & Col-0 & Merlot et al. 2002 \\
\hline & $a b a 3-2$ & Ler & Leung et al. 1997 \\
\hline & $\begin{array}{l}\text { abil-1, abi2-1 } \\
\text { abi4-101, abi4- }\end{array}$ & Ler & Leung et al. 1997 \\
\hline & 103 & Col- 0 & Finkelstein 1994 \\
\hline & abi5 & Col-0 & Finkelstein 1994 \\
\hline Oxidative burst & $\begin{array}{l}\text { rboh-D, rboh-F, } \\
\text { rbohD rboh-F }\end{array}$ & Col-0 & Torres et al. 2002 \\
\hline \multirow[t]{3}{*}{ Nitric oxide } & noal & Col- 0 & Zhao et al. 2007 \\
\hline & nial nia2 & Col-0 & Bright et al. 2006 \\
\hline & $\operatorname{csd} d, \operatorname{cs} d 2, f s d 1$ & Col-0 & $\begin{array}{l}\text { This work, SALK } \\
\text { collection }\end{array}$ \\
\hline \multirow[t]{3}{*}{ Cell death } & $\operatorname{vad1-1}$ & Col-0 & Lorrain et al. 2004 \\
\hline & hlm1-1 & Col-0 & Balagué et al. 2003 \\
\hline & $\operatorname{rcdl-1} 1$ & Col-0 & Overmyer et al. 2000 \\
\hline
\end{tabular}


For B. napus, total RNA was extracted from all the samples with the SV96 Total RNA Isolation System (Promega Corp., Charbonniéres-les-bains, France) according to the manufacturer's recommendations. RNA integrity was verified on the Agilent Bioanalyzer and the presence of potential genomic DNA was checked by Q-PCR on RNA. For each sample, $2 \mu \mathrm{g}$ of total RNA was submitted to RT using the high-capacity reverse transcription kit (Applied Biosystems, Courtabeouf, France) and random primers in $100 \mu \mathrm{l}$ (Supplementary Table 2 ). The RT reaction was then diluted to one tenth, and $2 \mu \mathrm{l}$ of cDNA was used for the amplification. Q-PCR was performed as above. Expression levels of mRNA for each gene were normalized using elongation factor $1-\alpha$, elongation factor $1-\beta$, glyceraldehyde-3-phosphate dehydrogenase, and polyubiquitin genes as internal standards. Relative expression was then considered as the $\Delta \mathrm{Cp}$ (according to Roche Diagnostics software LC480) between each gene and the average of controls. Experiments were done in triplicate. Average $\Delta \mathrm{Cp}$ was calculated from the three replicates and compared between infected and noninfected conditions. For this, the $\Delta \Delta \mathrm{Cp}$ and the $P$ value relative to the standard $t$ test were calculated.

\section{ROS and NO detection by microscopy.}

The method for NO detection in leaf tissue after S. sclerotiorum inoculation was adapted from Foissner and associates (2000). Discs from noninoculated plants and from the inoculated zone were incubated in the dark (45 min) in $10 \mu \mathrm{M}$ DAF-2DA (Sigma Chemical, Lille, France) dissolved in $50 \mathrm{mM}$ Tris- $\mathrm{HCl}$, $\mathrm{pH}$ 7.5. Fluorescence from diaminotriazolofluorescein, the reaction product of DAF-2DA with NO, was captured with a confocal laser scanning microscope (TCS SP2-SE; Leica, Wetzlar, Germany) using a $\times 63$ water-immersion objective lens. Leaves were excited with an argon laser $(488 \mathrm{~nm})$, fluorescence emission was recorded using the confocal channel 505 to $530 \mathrm{~nm}$, and autofluorescence of chloroplasts was captured with a 585nm log-pass filter. The same samples were also observed in bright-field microscopy. For fluorescence intensity measurement, the same protocol as for microscopy was applied on 10 inoculated discs and 5 noninoculated discs per ecotype or per mutant in wells of enzyme-linked immunosorbent assay plates using an FL600 microplate fluorescence reader (Fisher Scientific, Illkirch, France). Leaf areas infiltrated with L-NAME (1 $\mathrm{mM}$ ) (Sigma Chemical) were also tested.

In vivo determination of ROS release was performed using DAB and $\mathrm{H}_{2}$ DCF-DA (Sigma Chemical). Observations in bright field (DAB) or fluorescence $\left(\mathrm{H}_{2} \mathrm{DCFA}\right)$ were performed using a Leica MZ FLIII stereomicroscope as previously described (Lorrain et al. 2004). Determination of ROS levels ( $\mathrm{H}_{2} \mathrm{O}_{2}$ production) using $\mathrm{H}_{2}$ DCF-DA was done in the same conditions as NO measurement. Discs were cut from the leaves, were washed in morpholineethanesulfonic acid buffer (50 mM, pH 6.2), and were transferred to $200 \mu \mathrm{l}$ of fresh

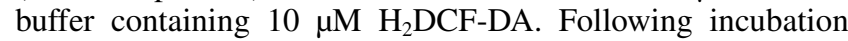
(30 $\mathrm{min}$ ), the fluorescence was measured as described above.

\section{ACKNOWLEDGMENTS}

We thank P. George (BIOGEMMA) for helping to set up the S. sclerotiorum inoculation protocol and preparation of the Brassica napus material preparation for expression analysis, D. Wendehenne for helpful discussions and for providing seeds of the nial nia2 mutant, and C. Gough for critical reading of the manuscript. This work was supported by a French ANR-Genoplante programme (ANR 06 GPLA 015).

\section{LITERATURE CITED}

Aarts, N., Metz, M., Holub, E., Staskawicz, B. J., Daniels, M. J., and Parker, J. E. 1998. Different requirements for EDS1 and NDR1 by disease resis- tance genes define at least two $R$ gene-mediated signaling pathways in Arabidopsis. Proc. Natl. Acad. Sci. U.S.A. 95:10306-10311.

Adie, B. A. T., Pérez-Pérez, J., Pérez-Pérez, M. M., Godoy, M., SanchezSerrano, J. J., Schmelz, E. A., and Solano, R. 2007. ABA is an essential signal for plant resistance to pathogens affecting JA biosynthesis and the activation of defenses in Arabidopsis. Plant Cell 19:1665-1681.

Andreasson, E., Jenkins, T., Brodersen, P., Thorgrimsen, S., Petersen, N. H., Zhu, S., Qiu, J. L., Micheelsen, P., Rocher, A., Petersen, M., Newman, M. A., Bjorn Nielsen, H., Hirt, H., Somssich, I., Mattsson, O., and Mundy, J. 2005. The MAP kinase substrate MKS1 is a regulator of plant defense responses. EMBO (Eur. Mol. Biol. Organ.) J. 24:2579-2589.

Asai, S., and Yoshioka, H. 2009. Nitric oxide as a partner of reactive oxygen species participates in disease resistance to necrotrophic pathogen Botrytis cinerea in Nicotiana benthamiana. Mol. Plant-Microbe Interact. 22: 619-629.

Asai, S., Ohta, K., and Yoshioka, H. 2008. MAPK signaling regulates nitric oxide and NADPH oxidase-dependent oxidative bursts in Nicotiana benthamiana. Plant Cell 20:1390-1406.

Austin, M. J., Muskett, P., Kahn, K., Feys, B. F., Jones, J. D., and Parker, J. E. 2002. Regulatory role of SGT1 in early $R$ gene-mediated plant defenses. Science 295:2077-2080.

Azevedo, C., Sadanandom, A., Kitagawa, K., Freialdenhoven, A., Shirasu, K., and Schulze-Lefert, P. 2002. The RAR1 interactor SGT1, an essential component of $R$ gene-triggered disease resistance. Science 295:2073-2076.

Bert, P. F., Jouan, I., Tourvieillede Labrouhe, D., Serre, F., Nicolas, P., and Vear, F. 2002. Comparative genetic analysis of quantitative traits in sunflower (Helianthus annuus) 1. QTL involved in resistance to Sclerotinia sclerotiorum and Diaporthe helianthii. Theor. Appl. Genet. 105:985993.

Besson-Bard, A., Pugin, A., and Wendehenne, D. 2008. New insights into nitric oxide signaling in plants. Annu. Rev. Plant Biol. 59:21-39.

Bittner-Eddy, P. D., and Beynon, J. L. 2001. The Arabidopsis downy mildew resistance gene, $R P P 13-N d$, functions independently of $N D R 1$ and EDS1 and does not require the accumulation of salicylic acid. Mol. Plant-Microbe Interact. 14:416-421.

Bouchez, O., Huard, C., Lorrain, S., Roby, D., and Balague, C. 2007. Ethylene is one of the key elements for cell death and defense response control in the Arabidopsis lesion mimic mutant vad1. Plant Physiol. 145:465-477.

Bright, J., Desikan, R., Hancock, J. T., Weir, I. S., and Neill, S. J. 2006. ABA-induced NO generation and stomatal closure in Arabidopsis are dependent on $\mathrm{H}_{2} \mathrm{O}_{2}$ synthesis. Plant J. 45:113-122.

Brodersen, P., Petersen, M., Bjorn Nielsen, H., Zhu, S., Newman, M. A., Shokat, K. M., Rietz, S., Parker, J., and Mundy, J. 2006. Arabidopsis MAP kinase 4 regulates salicylic acid- and jasmonic acid/ethylenedependent responses via EDS1 and PAD4. Plant J. 47:532-546.

Cao, H., Bowling, S. A., Gordon, S. A., and Dong, X. 1994. Characterization of an Arabidopsis mutant that is nonresponsive to inducers of systemic acquired resistance. Plant Cell 6:1583-1592.

Century, K. S., Holub, E. B., and Staskawicz, B. J. 1995. NDR1, a locus of Arabidopsis thaliana that is required for disease resistance to both a bacterial and a fungal pathogen. Proc. Natl. Acad. Sci. U.S.A. 92:65976601.

Cessna, S. G., Sears, V. E., and Dickman, M. B. 2000. Oxalic acid, a pathogenicity factor for Sclerotinia sclerotiorum, suppresses the oxidative burst of the host plant. Plant Cell 12:2191-2199.

Chae, H. S., Faure, F., and Kieber, J. J. 2003. The eto1, eto2, and eto3 mutations and cytokinin treatment increase ethylene biosynthesis in Arabidopsis by increasing the stability of ACS protein. Plant Cell 15:545-559.

Chao, Q., Rothemberg, M., Solano, R., Roman, G., Terzaghi, W., and Ecker, J. R. 1997. Activation of the ethylene gas response pathway in Arabidopsis by the nuclear protein ETHYLENE-INSENSITIVE3 and related proteins. Cell 89:1133-1144.

Dai, F.-M., Xu, T., Wolf, G. A., and He, Z.-H. 2006. Physiological and molecular features of the pathosystem Arabidopsis thaliana L-Sclerotinia sclerotiorum. J. Integr. Plant Biol. 48:44-52.

Delledone, M. 2005. NO news is good news for plants. Curr. Opin. Plant Biol. 8:390-396.

Desikan, R., S, A. H.-M., Hancock, J. T., and Neill, S. J. 2001. Regulation of the Arabidopsis transcriptome by oxidative stress. Plant Physiol. 127:159-172.

Desikan, R., Cheung, M. K., Bright, J., Henson, D., Hancock, J. T., and Neill, S. J. 2004. ABA, hydrogen peroxide and nitric oxide signalling in stomatal guard cells. J. Exp. Bot. 55:205-212.

de Torres-Zabala, M., Truman, W., Bennett, M. H., Lafforgue, G., Mansfield, J. W., Rodriguez Egea, P., Bogre, L., and Grant, M. 2007. Pseudomonas syringae pv. tomato hijacks the Arabidopsis abscisic acid signalling pathway to cause disease. EMBO (Eur. Mol. Biol. Organ.) J. 26:1434-1443. 
Donaldson, P. A., Anderson, T., Lane, B. G., Davidson, A. L., and Soimmonds, D. H. 2001. Soybean plants expressing an active oligomeric oxalate oxidase from the wheat gf-2.8 (germin) gene are resistant to the oxalete-secreting pathogen Sclerotinia sclerotiorum. Physiol. Mol. Plant Pathol. 59:297-307.

Eulgem, T., and Somssich, I. 2007. Networks of WRKY transcription factors in defense signaling. Curr. Opin. Plant Biol. 10:366-371.

Falk, A., Feys, B. J., Frost, L. N., Jones, J. D. G., Daniels, M. J., and Parker, J. E. 1999. EDS1, an essential component of $R$ gene-mediated disease resistance in Arabidopsis has homology to eukaryotic lipases. Proc. Natl. Acad. Sci. U.S.A. 96:3292-3297.

Feys, B., Benedetti, C. E., Penfold, C. N., and Turner, J. G. 1994. Arabidopsis mutants selected for resistance to the phytotoxin coronatine are male sterile, insensitive to methyl jasmonate, and resistant to a bacterial pathogen. Plant Cell 6:751-759.

Finkelstein, R. R. 1994. Mutations at two new Arabidopsis ABA response loci are similar to the abi3 mutations. Plant J. 5:765-771.

Flores-Pérez, U., Sauret-Güeto, S., Gas, E., Jarvis, P., and RodriguezConcepcion, M. 2008. A mutant impaired in the production of plastome-encoded proteins uncovers a mechanism for the homeostasis of isoprenoid biosynthetic enzymes in Arabidopsis plastids. Plant Cell 20:1303-1315.

Flors, V., Ton, J., Jakab, G., and Mauch-Mani, B. 2005. Abscisic acid and callose: Team players in defence against pathogens? J. Phytopathol. 153:377-383

Foissner, I., Wendehenne, D., Langebartels, C., and Durner, J. 2000. In vivo imaging of an elicitor-induced nitric oxide burst in tobacco. Plant J. 23:817-824.

Friedrich, L., Vernooij, B., Gaffney, T., Morse, A., and Ryals, J. 1995. Characterization of tobacco plants expressing a bacterial salicylate hydroxylase gene. Plant Mol. Biol. 29:959-968.

Garcia-Matta, C., and Lamattina, L. 2003. Abscisic acid, nitric oxide and stomatal closure - is nitrate reductase one of the missing links. Trends Plant Sci. 8:20-26.

Glazebrook, J. 2005. Contrasting mechanisms of defense against biotrophic and necrotrophic pathogens. Annu. Rev. Phytopathol. 43:205-227.

Glazebrook, J., Rogers, E. E., and Ausubel, F. M. 1996. Isolation of Arabidopsis mutants with enhanced disease susceptibility by direct screening. Genetics 143:973-982.

Godoy, G., Steadman, J. R., Dickman, M. B., and Dam, R. 1990. Use of mutants to demonstrate the role of axalic acid in pathogenicity of Sclerotinia sclerotiorum on Phaseolus vulgaris. Physiol. Mol. Plant Pathol. 37:179-191.

Govrin, E. M., and Levine, A. 2000. The hypersensitive response facilitates plant infection by the necrotrophic pathogen Botrytis cinerea. Curr. Biol. 10:751-757.

Guimaraes, R. L., and Stotz, H. U. 2004. Oxalate production by Sclerotinia sclerotiorum deregulates guard cells during infection. Plant Physiol. 136:3703-3711.

Guo, X., and Stotz, H. U. 2007. Defense against Sclerotinia sclerotiorum in Arabidopsis is dependent on jasmonic acid, salicylic acid and ethylene signaling. Mol. Plant Microbe Interact. 20:1384-1395.

Guzman, P., and Ecker, J. R. 1990. Exploiting the triple response of Arabidopsis to identify ethylene-related mutants. Plant Cell 2:513-523.

Hernandez-Blanco, C., Feng, D., Sanchez-Vallet, A., Deslandes, L., Llorente, F., Berrocal-Lobo, M., Keller, H., Barlet, X., SanchezRodriguez, C., Anderson, L., Somerville, S., Marco, Y., and Molina, A. 2007. Impairment of cellulose synthases required for Arabidopsis secondary cell wall formation enhances disease resistance. Plant Cell 19:890-903.

Huang, X., von Rad, U., and Durner, J. 2002. Nitric oxide induces transcriptional activation of the nitric oxide-tolerant alternative oxidase in Arabidopsis suspension cells. Planta 215:914-923.

Jirage, D., Tootle, T. L., Reuber, T. L., Frost, L. N., Feys, B. J., Parker, J. E., Ausubel, F. M., and Glazebrook, J. 1999. Arabidopsis thaliana PAD4 encodes a lipase-like gene that is important for salicylic acid signaling. Proc. Natl. Acad. Sci. U.S.A. 96:13583-13588.

Kaliff, M., Staal, J., Myrenas, M., and Dixelius, C. 2007. ABA is required for Leptosphaeria maculans resistance via ABI1- and ABI4-dependent signaling. Mol. Plant-Microbe Interact. 20:335-345.

Kim, S. K., Min, J.-Y., and Dickman, M. B. 2008. Oxalic acid is an elicitor of plant programmed cell death during Sclerotinia sclerotiorum disease development. Mol. Plant-Microbe Interact. 21:605-612.

Klibenstein, D. J., Monde, R. A., and Last, R. L. 1998. Superoxide dismutase in Arabidopsis: an eclectic enzyme family with disparate regulation and protein localization. Plant Physiol. 118:637-650.

Kunkel, B. N., and Brooks, D. M. 2002. Cross talk between signaling pathways in pathogen defense. Curr. Opin. Plant Biol. 5:325-331.

Leung, J., Merlot, S., and Giraudat, J. 1997. The Arabidopsis ABSCISIC ACID-INSENSITIVE2 (ABI2) and ABI1 genes encode homologous protein phosphatase $2 \mathrm{C}$ involved in abscisic acid signal transduction. Plant Cell 9:759-771.

Li, J., Brader, G., and Palva, E. T. 2004. The WRKY70 transcription factor: a node of convergence for jasmonate-mediated and salicylate-mediated signals in plant defense. Plant Cell 16:319-331.

Li, J., Brader, G., Kariola, T., and Tapio Palva, E. 2006. WRKY70 modulates the selection of signaling pathways in plant defense. Plant $\mathrm{J}$. 46:477-491.

Liu, S., Wang, H., Zhang, J., Fitt, B. D., Xu, Z., Evans, N., Liu, Y., Yang, W., and Guo, X. 2005. In vitro mutation and selection of double haploid Brassica napus lines with improved resistance to Sclerotinia sclerotiorum. Plant Cell Rep. 24:133-144.

Livingston, D. M., Hampton, J. L., Phipps, P. M., and Grabau, E. A. 2005. Enhancing resistance to Sclerotinia minor in peanut by expressing a barley oxalate oxidase gene. Plant Physiol. 137:1354-1362.

Lorenzo, O., and Solano, R. 2005. Molecular players regulating the jasmonate signalling network. Curr. Opin. Plant Biol. 8:532-540.

Lorenzo, O., Piqueras, R., Sanchez-Serrano, J. J., and Solano, R. 2003. ETHYLENE RESPONSE FACTOR1 integrates signals from ethylene and jasmonate pathways in plant defense. Plant Cell 15:165-178.

Lorenzo, O., Chico, J. M., Sanchez-Serrano, J. J., and Solano, R. 2004. JASMONATE-INSENSITIVE1 encodes a MYC transcription factor essential to discriminate between different jasmonate-regulated defense responses in Arabidopsis. Plant Cell 16:1938-1950.

Lorrain, S., Lin, B., Auriac, M-C., Kroj, T., Saindrenan, P., Nicole, M., Balagué, C., and Roby, D. 2004. VASCULAR ASSOCIATED DEATH 1 , a novel GRAM domain-containing protein, is a regulator of cell death and defense responses in vascular tissues. Plant Cell 16:22172232

Concerning the query 6 , the DCp is the difference between of the Cp of the gene of interest and the reference gene

Mauch-Mani, B., and Mauch, F. 2005. The role of abscisic acid in plantpathogen interactions. Curr. Opin. Plant Biol. 8:409-414.

McDowell, J. M., and Dangl, J. L. 2000. Signal transduction in the plant immune response. Trends Biochem. Sci. 25:81-85.

McKhann, H. I., Camilleri, C., Berard, A., Bataillon, T., David, J. L., Reboud, X., Le Corre, V., Caloustian, C., Gut, I. G., and Brunel, D. 2004. Nested core collections maximizing genetic diversity in Arabidopsis thaliana. Plant J. 38:193-202.

Merlot, S., Mustilli, A. C., Genty, B., North, H., Lefebvre, V., Sotta, B. Vavasseur, A., and Giraudat, J. 2002. Use of infrared thermal imaging to isolate Arabidopsis mutants defective in stomatal regulation. Plant J. 30:601-609.

Mittler, R., Vanderauwera, S., Gollery, M., and Van Breusegem, F. 2004 Reactive oxygen gene network of plants. Trends Plant Sci. 9:490-498.

Modolo, L. V., Augusto, O., Almeida, I. M., Magalhaes, J. R., and Salgado, I. 2005. Nitrite as the major source of nitric oxide production by Arabidopsis thaliana in response to Pseudomonas syringae. FEBS (Fed. Eur. Biochem. Soc.) Lett. 17:3814-3820.

Muskett, P. R., Kahn, K., Austin, M. J., Moisan, L. J., Sadanandom, A., Shirasu, K., Jones, J. D., and Parker, J. E. 2002. Arabidopsis RAR1 exerts rate-limiting control of $R$ gene-mediated defenses against multiple pathogens. Plant Cell 14:979-992.

Overmyer, K., Tuominen, H., Kettunen, R., Betz, C., Langebartels, C., Sandermann, H., and Kangasjärvi, J. 2000. Ozone-sensitive Arabidopsis rcdl mutant reveals opposite roles for ethylene and jasmonate signaling pathways in regulating superoxide-dependent cell death. Plant Cell 12:1849-1862.

Parani, M., Rudrabhatla, S., Myers, R., Weirich, H., Smith, B., Leaman, D. W., and Glodman, S. L. 2004. Microarray analysis of nitric oxide responsive transcripts in Arabidopsis. Plant Biotechnol. J. 2:359-366.

Parker, J. E., Holub, E. B., Frost, L. N., Falk, A., Gunn, N. D., and Daniels, M. J. 1996. Characterization of eds1, a mutation in Arabidopsis suppressing resistance to Peronospora parasitica specified by several different RPP genes. Plant Cell 8:2033-2046.

Petersen, M., Brodersen, P., Naested, H., Andreasson, E., Lindhart, U., Johansen, B., Nielsen, H. B., Lacy, M., Austin, M. J., Parker, J. E., Sharma, S. B., Klessig, D. F., Martienssen, R., Mattsson, O., Jensen, A. B., and Mundy, J. 2000. Arabidopsis map kinase 4 negatively regulates systemic acquired resistance. Cell 103:1111-1120.

Purdy, L. H. 1979. Sclerotinia sclerotiorum: history, diseases and symptomology, host range, geographic distribution and impact. Phytopathology 69:875-880.

Riou, C., Freyssinet, G., and Fevre, M. 1991. Production of cell wall degrading enzymes by the phytopathogenic fungus Sclerotinia sclerotiorum. Appl. Environ. Microbiol. 57:1478-1484.

Rogers, E. E., and Ausubel, F. M. 1997. Arabidopsis enhanced disease susceptibility mutants exhibit enhanced susceptibility to several bacterial pathogens and alterations in $P R-1$ gene expression. Plant Cell 9:305316. 
Rojo, E., Solano, R., and Sanchez-Serrano, J. J. 2003. Interactions between signaling compounds involved in plant defense. J. Plant Growth Regul. 22:82-98.

Roman, G., Lubarsky, B., Kieber, J. J., Rothenberg, M., and Ecker, J. R. 1995. Genetic analysis of ethylene signal transduction in Arabidopsis thaliana: five novel mutant loci integrated into a stress response pathway. Genetics 139:1393-1409.

Schoonbeek, H.-J., Jacquat-Bovet, A.-C., Mascher, F., and Métraux, J.-P. 2007. Oxalate-degrading bacteria can protect Arabidopsis thaliana and crop plants against Botrytis cinerea. Mol. Plant-Microbe Interact. 20:1535-1544.

Staswick, P., and Tiryaki, I. 2004. The oxylipin signal jasmonic acid is activated by an enzyme that conjugates it to isoleucine in Arabidopsis. Plant Cell 16:2117-2127.

Staswick, P. E., Su, W., and Howell, S. H. 1992. Methyl jasmonate inhibition of root growth and induction of a leaf protein are decreased in an Arabidopsis thaliana mutant. Proc. Natl. Acad. Sci. U.S.A. 89:68376840

Thines, B., Katsir, L., Melotto, M., Niu, Y., Mandaokar, A., Liu, G., Nomura, K., He, S. Y., Howe, G. A., and Browse, J. 2007. JAZ repressor proteins are targets of the $\mathrm{SCF}(\mathrm{COI} 1)$ complex during jasmonate signalling. Nature 448:661-665.

Thomma, B. P., Penninckx, I. A., Broekaert, W. F., and Cammue, B. P. 2001. The complexity of disease signaling in Arabidopsis. Curr. Opin. Immunol. 13:63-68.

Ton, J., and Mauch-Mani, B. 2004. Beta-amino-butyric acid induced resistance against necrotrophic pathogens is based on ABA-dependent priming for callose. Plant J. 38:119-130.

Tör, M., Gordon, P., Cuzick, A., Eulgem, T., Sinapidou, E., Mert-Turk, F., Can, C., Dangl, J. L., and Holub, E. B. 2002. Arabidopsis SGT1b is required for defense signaling conferred by several downy mildew resistance genes. Plant Cell 14:993-1003.

Tornero, P., Chao, R. A., Luthin, W. N., Goff, S. A., and Dangl, J. L. 2002. Large-scale structure-function analysis of the Arabidopsis RPM1 disease resistance protein. Plant Cell 14:435-450.

Torres, M. A., Dangl, J. L., and Jones, J. D. 2002. Arabidopsis gp91phox homologues AtrbohD and AtrbohF are required for accumulation of reactive oxygen intermediates in the plant defense response. Proc. Natl. Acad. Sci. U.S.A. 99:517-522.

Vogel, J., Woeste, K. E., Theologis, A., and Kieber, J. J. 1998. Recessive and dominant mutations in the ethylene biosynthetic gene ACS5 of Arabidopsis confer cytokinin insensitivity and ethylene overproduction, respectively. Proc. Natl. Acad. Sci. U.S.A. 95:4766-4771.

Wang, A. R., Lin, W. W., Chen, X. T., Lu, G. D., Zhou, J., and Wang, Z. H 2008. Isolation and identification of Sclerotinia stem rot causal pathogen in Arabidopsis thaliana. J. Zhejiang Univ. Sci. B 9:818-822.

Wang, Z., Mao, H., Dong, C., Ji, R., Cai, L., Fu, H., and Liu, S. 2009. Overexpression of Brassica napus MPK4 enhances resistance to Sclerotinia sclerotiorum in oilseed rape. Mol. Plant-Microbe Interact. 22:235-244.

Wendehenne, D., Durner, J., and Klessig, D. F. 2004. Nitric oxide: a new player in plant signalling and defense responses. Curr. Opin. Plant Biol. 7:449-455.

Whenham, R., Fraser, R. S. S., Brown, L. P., and Payne, J. A. 1986. Tobacco mosaic virus-induced increase in abscisic acid concentration in tobacco leaves: intracellular location in light and dark green areas and relationship to symptom development. Planta 168:592-598.

Wildermuth, M. C., Dewdney, J., Wu, G., and Ausubel, F. M. 2001. Isochorismate synthase is required to synthesize salicylic acid for plant defence. Nature 414:562-565.

Wilkinson, J. Q., and Crawford, N. M. 1993. Identification and characterization of a chlorate-resistant mutant of Arabidopsis thaliana with mutations in both nitrate reductase structural genes NIA1 and NIA2. Mol. Gen. Genet. 239:289-297.

Woeste, K. E., Ye, C., and Kieber, J. J. 1999. Two Arabidopsis mutants that overproduce ethylene are affected in the posttranscriptional regulation of 1-aminocyclopropane-1-carboxylic acid synthase. Plant Physiol. 119:521-529

Yamasaki, H., and Sakihama, Y. 2000. Simultaneous production of nitric oxide and peroxynitrite by plant nitrate reductase: in vitro evidence for the NR-dependent formation of active nitrogen species. FEBS (Fed. Eur. Biochem. Soc.) Lett. 468:89-92.

Yang, B., Srivastava, S., Deyholos, M. K., and Kav, N. N. V. 2007. Transcriptional profiling of canola (Brassica napus L.) responses to the fungal pathogen Sclerotinia sclerotiorum. Plant Sci. 173:156-171.

Zago, E., Morsa, S., Dat, J. F., Alard, P., Ferrarini, A., Inze, D., Delledone, M., and Van Breusegem, F. 2006. Nitric oxide and hydrogen peroxideresponsive gene regulation during cell death induction in tobacco. Plant Physiol. 141:404-411.

Zeidler, D., Zahringer, U., Gerber, I., Dubery, I., Hartung, T., Bors, W., Hutzler, P., and Durner, J. 2004. Innate immunity in Arabidopsis thaliana: lipopolysaccharides activate nitric oxide synthase (NOS) and induce defense genes. Proc. Natl. Acad. Sci. U.S.A. 101:15811-15816.

Zhao, J., and Meng, J. 2003. Genetic analysis of loci associated with partial resistance to Sclerotinia sclerotiorum in rapeseed (Brassica napus L.). Theor. Appl. Genet. 106:759-764.

Zhao, J., Udall, J. A., Quijada, P. A., Grau, C. R., Meng, J., and Osborn, T. C. 2006a. Quantitative trait loci for resistance to Sclerotinia sclerotiorum and its association with a homologous non-reciprocal transposition in Brassica napus L. Theor. Appl. Genet. 112:509-516.

Zhao, J., Wang, J., An, L., Doerge, R. W., Chen, Z. J., Grau, C. R., Meng, J., and Osborn, T. C. 2006b. Analysis of gene expression profiles in response to Sclerotinia sclerotiorum in Brassica napus. Planta 227:13-24

Zhao, M. G., Tian, Q. Y., and Zhang, W. H. 2007. Nitric oxide synthasedependent nitric oxide production is associated with salt tolerance in Arabidopsis. Plant Physiol. 144:206-217.

\section{AUTHOR-RECOMMENDED INTERNET RESOURCE}

INRA VNAT webservice:

dbsgap.versailles.inra.fr/vnat/Fichier_collection/Rech_core_coll48.php 